\title{
Laser-generated high entropy metallic glass nanoparticles bifunctional electrocatalysts
}

\author{
Jacob Johny ${ }^{1}$, Yao Li ${ }^{1}$, Marius Kamp ${ }^{2}$, Oleg Prymak ${ }^{3}$, Shun-Xing Liang ${ }^{1}$, Tobias Krekeler ${ }^{4}$, Martin Ritter ${ }^{4}$, \\ Lorenz Kienle $^{2}$, Christoph Rehbock ${ }^{1}$, Stephan Barcikowski ${ }^{1}(\bowtie)$, and Sven Reichenberger ${ }^{1}$ \\ ${ }^{1}$ Technical Chemistry I and Center for Nanointegration Duisburg-Essen (CENIDE), University of Duisburg-Essen, Essen 45141, Germany \\ ${ }^{2}$ Institute for Materials Science, Synthesis and Real Structure, Kiel University, Kiel 24143, Germany \\ ${ }^{3}$ Inorganic Chemistry and Center for Nanointegration Duisburg-Essen (CENIDE), University of Duisburg-Essen, Essen 45141, Germany \\ ${ }^{4}$ Electron Microscopy Unit, Hamburg University of Technology, Hamburg 21073, Germany
}

(c) The Author(s) 2021

Received: 31 May 2021 / Revised: 30 July 2021 / Accepted: 10 August 2021

\begin{abstract}
High entropy metallic glass nanoparticles (HEMG NPs) are very promising materials for energy conversion due to the wide tuning possibilities of electrochemical potentials offered by their multimetallic character combined with an amorphous structure. Up until now, the generation of these HEMG NPs involved tedious synthesis procedures where the generated particles were only available on highly specialized supports, which limited their widespread use. Hence, more flexible synthetic approaches to obtain colloidal HEMG NPs for applications in energy conversion and storage are highly desirable. We utilized pulsed laser ablation of bulk high entropy alloy targets in acetonitrile to generate colloidal carbon-coated CrCoFeNiMn and CrCoFeNiMnMo HEMG NPs. An in-depth analysis of the structure and elemental distribution of the obtained nanoparticles down to single-particle levels using advanced transmission electron microscopy (TEM), energy-dispersive X-ray spectroscopy (EDX), X-ray diffraction (XRD), and Xray photoelectron spectroscopy (XPS) methods revealed amorphous quinary and senary alloy phases with slight manganese oxide/hydroxide surface segregation, which were stabilized within graphitic shells. Studies on the catalytic activity of the corresponding carbon-HEMG NPs during oxygen evolution and oxygen reduction reactions revealed an elevated activity upon the incorporation of moderate amounts of Mo into the amorphous alloy, probably due to the defect generation by atomic size mismatch. Furthermore, we demonstrate the superiority of these carbon-HEMG NPs over their crystalline analogies and highlight the suitability of these amorphous multi-elemental NPs in electrocatalytic energy conversion.
\end{abstract}

\section{KEYWORDS}

high entropy alloy, pulsed laser ablation in liquid, amorphous, catalysis, oxygen evolution reaction, oxygen reduction reaction

\section{Introduction}

Nanoparticles (NPs) containing multiple metallic elements are of interest for various industrial and technological applications where different mechanical [1] or catalytical [2] properties of each constituent metal are combined within a single NP [3-7]. Among the multimetallic systems, high entropy alloys (HEAs) represent a relatively new material class of single-phase complex solid solutions (CSS) [8-11]. The entropic part hereby supports the formation of the solid solution often becoming significant for equimolar mixtures of five or more principal elements arranged in a simple, usually crystalline cubic (face-centered cubic (fcc) or body-centered cubic (bcc)) structure. The configurational entropy further stabilizes the active sites besides serving as highperformance electrocatalysts [12]. Please note that the concept of entropic stabilization is highly disputed in the community, and it is currently believed that an interplay between mixing enthalpy and mixing entropy is involved, while the predominance of either effect is highly dependent on the material system $[13,14]$. Nonetheless, we will use the expression HEA throughout this manuscript as it is deeply rooted in the discourse. It is well established that a rational design of HEA composition allows controlling their physicochemical properties at the nanoscale and performance, e.g., in catalysis $[12,15,16]$ and energy storage [17-19]. Due to these unique interactions of distinct neighboring metal atoms [2], HEA NPs are discussed and developed as very promising candidates to replace established but scarce and expensive noble metals in catalytic reactions such as oxygen evolution [20-24], oxygen reduction [2, 25, 26], methanol oxidation [27-29], $\mathrm{CO}_{2}$ reduction [30,31] and hydrogen evolution $[22,32,33]$. As a potential reason for the outstanding catalytic performance of HEA NPs, the presence of multiple, energetically different adsorption sites on the catalyst [2] forming an adsorption energy distribution pattern (AEDP) [34] is frequently discussed. For instance, density functional theory calculations were used to determine the AEDP in different CoCuGaNiZn and $\mathrm{AgAuCuPdPt}$ alloys aiming at adsorption of $\mathrm{OH}$ and $\mathrm{O}$ species in the oxygen reduction reaction [26] and the co-adsorption of $\mathrm{H}$ and $\mathrm{CO}$ in $\mathrm{CO}_{2}$ reduction reactions [31]. These findings revealed patterns of adsorption energy peaks, each associated with a 
designated element. Further studies also highlighted that these AEDP can be experimentally correlated with changes in the shape of electrocatalytic response curves upon replacement of elements [34] or changes in the alloy composition using inflection point analysis [35]. Although crystalline HEAs have been at the center of research so far, high entropy metallic glass (HEMG) NPs can exhibit advanced electrocatalytic properties due to their disordered atomic arrangement $[22,36,37]$. In the case of HEMG, the higher concentration of coordinatively unsaturated sites, better corrosion resistance, denser distribution of defects, more loosely bound atoms, and larger potential energy are additional desirable features [37-39]. While HEA usually refers to a multimetallic system having a high entropy and a simple crystalline structure (e.g., fcc or bcc), HEMG denotes a system having an amorphous structure where the associated high configurational entropy is preserved [40].

Owing to their significant technological potential, nanometric HEAs were successfully obtained through a number of synthetic routes including physical vapor deposition [41], carbothermal shockwave technique [42], aerosol synthesis [9], and wet chemical synthesis [43]. Recently, monodisperse 2 nm HEA NPs consisting of up to ten elements were obtained on granular supports by a fastmoving bed pyrolysis method [32]. As in this example, most of the previously mentioned synthesis methods give access to supported or powdered HEA NPs when employing sophisticated temperature and pressure conditions that need to be optimized for each individual component and support used [12,42]. As a complementary method, pulsed laser ablation in liquid (PLAL) is an established and scalable room-temperature approach to synthesize compositional series of colloidal and supported alloy NPs for catalytic studies [44-46]. Here, the obtained colloidal alloy NPs often resemble the composition of the bulk alloy targets used for ablation $[47,48]$, though deviations may occur upon utilization of ultrashort pulses and element systems with huge miscibility gaps $[49,50]$. This synthesis route is already well established for binary and ternary alloy NPs $[48,51]$ and PLAL was recently employed for generating HEA NPs as well $[35,52]$. Waag et al. demonstrated the potential of the PLAL technique in bulk scale production of HEA NPs by producing up to 3 grams of cantor alloy (CrCoFeNiMn) NPs per hour [52]. However, it should be noted that the HEA NPs obtained by this synthesis route were primarily crystalline. With the high heating and cooling rates of more than $10^{10} \mathrm{~K} / \mathrm{s}$ during some particle formation processes in PLAL from the ablation plume, the NP formation is kinetically quenched $[46,48,53,54]$. Under these favorable conditions, the formation of amorphous oxide and carbide NPs [55-58], as well as high defect densities favorable for catalysis $[57,58]$, have been found previously in PLAL. Due to their enhanced electrochemical properties, the synthesis of HEMG nanostructures is not only of prime relevance for applications in energy conversion and catalysis but also highly interesting from a fundamental point of view.

Herein, we report the synthesis of quinary (CrCoFeNiMn) and senary (CrCoFeNiMnMo) HEMG NPs by pulsed laser ablation in acetonitrile. We exploit acetonitrile to produce thin graphitic layers around the NPs to possibly stabilize the amorphous phase in the high entropy systems. Furthermore, the inclusion of different Mo molar fractions into the CrCoFeNiMn base alloy is systematically investigated and correlated changes in structure, elemental distribution, and surface composition are assessed. Finally, we explore the suitability of the generated HEMG NPs as electrocatalysts for oxygen evolution and oxygen reduction reactions (OER and ORR, respectively) where the degree of amorphization in the generated NP ensembles, as well as the incorporated content of $\mathrm{Mo}$, influence the catalytic performance.

\section{Experimental}

\subsection{HEMG NPs synthesis}

CrCoFeNiMn HEMG NPs with 30\% $\mathrm{Mn}$ and the molar composition of other elements (i: $\mathrm{Cr}_{17.5} \mathrm{Co}_{17.5} \mathrm{Fe}_{17.5} \mathrm{Ni}_{17.5} \mathrm{Mn}_{30}$ ) were generated by pulsed laser ablation of a respective HEA target of the given composition in acetonitrile (99.9\%, VWR chemicals). To study the effect of Mo on the gained nanoparticle structure and catalytic activity, CrCoFeNiMnMo HEMG NPs with three different Mo contents $\left(\mathrm{Mo}_{6}, \mathrm{Mo}_{14}\right.$, and $\left.\mathrm{Mo}_{30}\right)$ were synthesized in the same manner. Within each target used for the synthesis of these three samples, $30 \%$ of $\mathrm{Mn}$, previously found optimal for ORR activity [35], was maintained. The respective Mo content was induced by equally replacing the other four elements $\mathrm{Cr}, \mathrm{Co}, \mathrm{Fe}$, and $\mathrm{Ni}$ such that the following molar compositions were used:

ii: $\mathrm{Cr}_{16} \mathrm{Co}_{16} \mathrm{Fe}_{16} \mathrm{Ni}_{16} \mathrm{Mn}_{30} \mathrm{Mo}_{6}$,

iii: $\mathrm{Cr}_{14} \mathrm{Co}_{14} \mathrm{Fe}_{14} \mathrm{Ni}_{14} \mathrm{Mn}_{30} \mathrm{Mo}_{14}$, and

iv: $\mathrm{Cr}_{10} \mathrm{Co}_{10} \mathrm{Fe}_{10} \mathrm{Ni}_{10} \mathrm{Mn}_{30} \mathrm{Mo}_{30}$.

Each HEA bulk target was prepared by pressing mixed micro powders (Alfa Aesar, Haverhill, USA, > 99\%, < $10 \mu \mathrm{m}$ ) of the elements $(\mathrm{Cr}, \mathrm{Co}, \mathrm{Fe}, \mathrm{Ni}, \mathrm{Mn}$, and $\mathrm{Mo}$ ) at respective atomic ratios in a hydraulic press followed by sintering in Ar atmosphere at $1,100{ }^{\circ} \mathrm{C}$ for $5 \mathrm{~h}$. The chemical compositions of the HEA targets were determined by scanning electron microscopy-energydispersive X-ray spectroscopy (SEM-EDX, Philips-XL 30) as well as X-ray fluorescence spectroscopy (XRF, S8 TIGER, Bruker, Billerica, USA). EDX maps of the desired elements were acquired for the representative $\mathrm{Cr}_{16} \mathrm{Co}_{16} \mathrm{Fe}_{16} \mathrm{Ni}_{16} \mathrm{Mn}_{30} \mathrm{Mo}_{6}$ composition for the elemental distribution. For the synthesis of colloidal NPs, a nanosecond pulsed Nd:YAG laser (Rofin-Sinar RS-Marker 100D) having a fundamental wavelength of $1064 \mathrm{~nm}$, a repetition rate of $10 \mathrm{kHz}$, a laser pulse energy of $6 \mathrm{~mJ}$, and a pulse duration of $40 \mathrm{~ns}$ was used. The laser beam was focused using an $f$-theta lens $(f=$ $63 \mathrm{~mm}$ ) and scanned in a spiral pattern on the target surface during the ablation using a galvanometric scanner. Laser ablation was performed in a continuous flow chamber with a constant flow rate of acetonitrile at $80 \mathrm{~mL} / \mathrm{min}$. The liquid flow during ablation was controlled using a peristaltic pump (ISM321C, Ismatec). This enabled minimum post-irradiation of the generated HEMG NPs by the incoming laser pulses as well as continuous processing of the HEMG NPs for catalysis applications. The so-obtained HEA nanocolloids were stored in tight glass vials under ambient conditions and subsequently used for further characterization and catalysis.

\subsection{Powder X-ray diffraction (XRD)}

XRD (Bruker D8 Advance, CuK $\alpha$ with $\lambda=1.54 \AA$ at $40 \mathrm{kV}, 40$ $\mathrm{mA}$ ) was employed for the structural characterization of the lasergenerated HEMG NPs. The XRD samples were prepared by drying drop-casted concentrated HEMG NP suspensions on single-crystal Si sample holders to exclude scattering from the sample holder. The measurements were carried out in the BraggBrentano geometry using a step size of $0.01^{\circ}$ and a counting time of $1.5 \mathrm{~s}$. The qualitative phase analysis was done with the Diffrac.EVA VI software from Bruker using the NiFe fcc phase (\#03-1209) from the ICDD database as a reference. Rietveld refinement was performed on collected diffractograms using TOPAS 5.0 software from Bruker to determine the lattice parameters and crystallite sizes of the fcc phase. Before acquiring the diffractograms, an instrumental characterization with a standard $\mathrm{LaB}_{6}$ powder (SRM 660b from NIST) was performed.

\subsection{Transmission electron microscopy (TEM)}

TEM analysis including selected area electron diffraction (SAED), 
high-resolution TEM (HRTEM), scanning TEM (STEM), and energy-dispersive X-ray spectroscopy (EDX) was performed with a JEOL JEM 2100 and a FEI Talos F200X equipped with a chemiSTEM EDX detector system. Imaging in high-angle annular dark-field (HAADF)-STEM mode, permits atomic-number dependent Z-contrast. The samples for the TEM analysis were prepared by drop-casting NPs colloid on copper and aluminum grids with a lacey carbon film (Plano $\mathrm{GmbH}$ ) at ambient temperature. After preparation, the TEM grids were permanently stored in a vacuum chamber to avoid contamination and oxidation from the ambient atmosphere.

\subsection{X-ray photoelectron spectroscopy (XPS)}

XPS was employed to gain information on the surface oxidation state of different elements in the HEMG NPs. The XPS samples were prepared by drying a few drops of the respective HEMG NPs colloids on $\mathrm{Si}$ wafers followed by drying at ambient conditions. XPS spectra were recorded with a VersaProbe IITM from UlvacPhi using the $\mathrm{Al}-\mathrm{K} \alpha$ line at $1,486.6 \mathrm{eV}$ and a spot size of $100 \mu \mathrm{m}$ at an energetic resolution of $0.5 \mathrm{eV}$. A dual-beam charge neutralization and a hemispherical analyzer (with an angle of $45^{\circ}$ between the sample surface and the analyzer) were used for the measurements. The acquired high-resolution XPS spectra were corrected according to the binding energy of the graphitic $\mathrm{C}$ $(284.8 \mathrm{eV})$ determined during deconvolution of the $\mathrm{C} 1 \mathrm{~s}$ spectrum of each sample. The peak deconvolutions were performed using the CasaXPS software applying a Shirley-type background [59] and fitting parameters presented in Table S1 in the Electronic Supplementary Material (ESM).

\subsection{Electrochemical analysis}

\subsubsection{Catalyst preparation}

The electrocatalysts were obtained by directly flowing the lasergenerated HEMG NPs into a suspension of carbon black (VULCAN XC72R, Cabot Corporation, Boston, USA) in acetonitrile. All catalysts were prepared at a constant mass loading of 20 wt.\% (HEMG NPs in HEMG/C). The produced HEMG/C catalysts were first placed in an ultrasonic bath for $20 \mathrm{~min}$ and then concentrated using a rotary evaporator. The final catalysts were collected by centrifugation of the highly concentrated HEMG/C dispersion and subsequently dried at ambient conditions to obtain powder samples. A three-electrode potentiostat (VersaSTAT F3, Princeton Applied Research, Ametek, Berwyn, USA) was employed for the electrochemical analysis.

\subsubsection{OER measurement}

The OER measurements were performed in a $0.1 \mathrm{M} \mathrm{NaOH}$ electrolyte using the HEMG/C catalyst as the working electrode, Pt wire as the counter electrode, and $\mathrm{Ag} / \mathrm{AgCl}$ as the reference electrode. The HEMG/C catalyst inks for the OER tests were prepared by dispersing $\sim 5 \mathrm{mg}$ of the respective catalyst into $5 \mathrm{~mL}$ Milli-Q water-isopropanol (Thermo Fisher Scientific) mixture (1:1 by volume) containing $40 \mu \mathrm{L}$ Nafion ionomer solution (5 wt.\%, 15\%-20\% water, Sigma Aldrich, St. Louis, USA) followed by ultrasonication. Subsequently, $10 \mu \mathrm{L}$ of the catalyst ink was dropcasted on the glassy carbon electrode and dried by rotating at 700 rpm for $20 \mathrm{~min}$. The electrolyte was degassed using $\mathrm{N}_{2}$ for $15 \mathrm{~min}$ before each measurement. A sweep rate of $100 \mathrm{mV} / \mathrm{s}$ was used for acquiring the blank cyclic voltammograms where the electrodes were not rotated. All linear sweep measurements were performed at a scan rate of $20 \mathrm{mV} / \mathrm{s}$ in a potential window of 0.9 to $1.75 \mathrm{~V}$ vs. reversible hydrogen electrode (RHE).

\subsubsection{ORR measurement}

For the ORR measurements, Pt wire and $\mathrm{Ag} / \mathrm{AgCl}$ were used as the counter and reference electrodes, respectively. The catalyst inks for ORR were prepared by dispersing $\sim 5 \mathrm{mg}$ of the respective HEMG/C powder into a $1 \mathrm{~mL}$ water-ethanol mixture (1:1 by volume) containing $2 \%$ Nafion and sonicated for $15 \mathrm{~min}$. Then $8.27 \mu \mathrm{L}$ of the ink was drop-casted on a glassy carbon electrode to achieve a mass loading of $0.21 \mathrm{mg} / \mathrm{cm}^{2}$. The electrodes were dried at atmospheric conditions for 1 h. $0.1 \mathrm{M} \mathrm{NaOH}$ was used as the electrolyte for the ORR measurements. The ORR measurements were started with a conditioning step comprising 40 cycles at 80 $\mathrm{mV} / \mathrm{s}$ in a potential window of 1.0 to $0 \mathrm{~V}$ vs. RHE, followed by the electrochemical impedance spectroscopy (EIS) measurement, and a linear sweep voltammogram (LSV) in $\mathrm{N}_{2}$-saturated and $\mathrm{O}_{2}$ saturated electrolyte at $10 \mathrm{mV} / \mathrm{s}$ at $1,600 \mathrm{rpm}$. The EIS (with a frequency ranging from $50 \mathrm{kHz}$ to $10 \mathrm{~Hz}$ at open circuit potential with an AC perturbation of $10 \mathrm{mVpp}$ ) data was used to determine the $i R$ drop in ORR. All measured potentials of the ORR-LSVs are hence $i R$-compensated. Potentials of both OER and ORR were calibrated with respect to the potential of a standard RHE. The OER and ORR tests of the $\mathrm{Cr}_{16} \mathrm{Co}_{16} \mathrm{Fe}_{16} \mathrm{Ni}_{16} \mathrm{Mn}_{30} \mathrm{Mo}_{6}$ HEMG/C catalysts were repeated 3 additional times for calculating the experimental error in each case and the relative error from these measurements were considered in all other HEA compositions.

\section{Results and discussion}

To characterize the structure, morphology, elemental distribution, and surface composition of the colloidal quinary and senary HEMG NPs obtained by laser ablation in acetonitrile using nanosecond pulses, a combination of various nanocharacterization methods was conducted including TEM/STEM, EDX, SAED, XRD, and XPS. Figure 1 shows the size distributions of the laser-generated HEMG NPs obtained from the TEM analysis by measuring the Ferret diameter of more than 250 NPs in each sample. All samples show a broad size distribution in the range of 10-30 $\mathrm{nm}$ irrespective of the compositions in the ablation targets. Here, the sample with the highest Mo composition exhibits a more pronounced bimodality which is known in PLAL and has been linked to the dynamics of the hot molten plume that is induced by the laser pulse when ablating the target $[54,60]$. Particularly for longer pulse duration, three regimes were identified by molecular dynamics (MD) simulation that lead to different particle sizes and may have been affected by Mo due to its nearly two times higher melting temperature compared to the other elements present in the target. Consequently, a compositiondependent dynamics of the plume is likely but has not yet been addressed by the MD simulations up until now. The polydispersity index (PDI) of all samples was in the range of 0.16 to 0.84 while only size distributions with a PDI $<0.1$ can be referred to as monodisperse [61]. The higher PDI values and presence of smaller $(<10 \mathrm{~nm})$ and larger size fractions $(\sim 10-30)$ of all samples indicate a rather bimodal nature $[62,63]$ of the HEA NPs which is well known for colloidal NPs gained from PLAL and is attributed to the dynamics of the plume [53] as previously discussed. Numerous additional size reduction steps such as exsitu [64] or in-situ laser fragmentation [65], in-situ adsorption [66], continuous tubular centrifugation [67], or size quenching with electrostatic or steric additives [46] can be applied to gain narrow monomodal size distributions. However, as size reduction steps further interfere with particle growth and the structure of the resulting NPs, these techniques were avoided in this compositional study. Overall, all compositions were found to express a similar specific surface area (Fig. 1) which was mandatory to compare the compositions regarding their overall catalyst performance. STEM- 

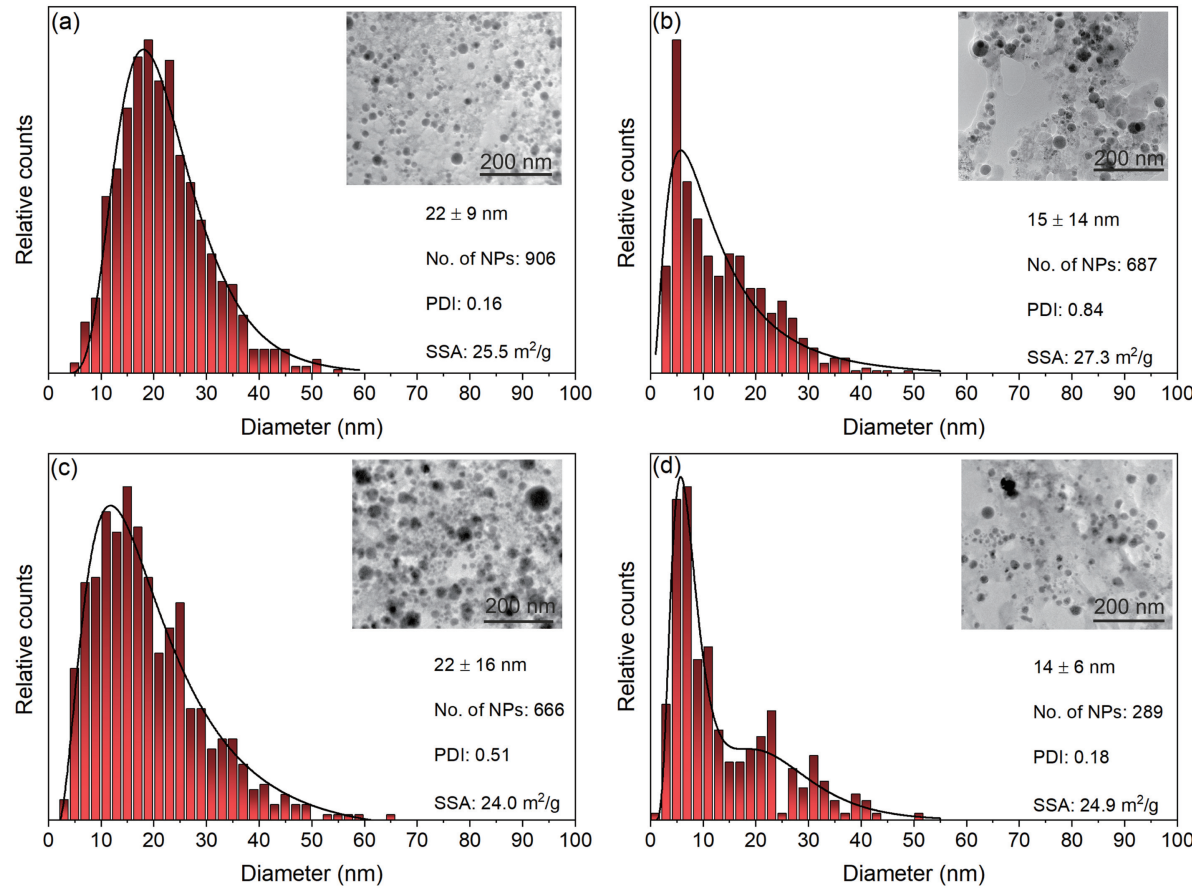

Figure 1 Particle size distribution of (a) $\mathrm{Cr}_{17.5} \mathrm{Co}_{17.5} \mathrm{Fe}_{17.5} \mathrm{Ni}_{17.5} \mathrm{Mn}_{30}$, (b) $\mathrm{Cr}_{16} \mathrm{Co}_{16} \mathrm{Fe}_{16} \mathrm{Ni}_{16} \mathrm{Mn}_{30} \mathrm{Mo}_{06}$, (c) $\mathrm{Cr}_{14} \mathrm{Co}_{14} \mathrm{Fe}_{14} \mathrm{Ni}_{14} \mathrm{Mn}_{30} \mathrm{Mo}_{14}$, and $_{\text {(d) }} \mathrm{Cr}_{10} \mathrm{Co}_{10} \mathrm{Fe}_{10} \mathrm{Ni}_{10} \mathrm{Mn}_{30} \mathrm{Mo}_{30}$ NPs with a log-normal fitting. The size distributions were produced by measuring the Ferret diameter of 289-906 NPs from several TEM images of the corresponding samples. Representative TEM images corresponding to each composition are given in the insets and the mean particle diameter, standard deviation, PDI, and specific surface area (SSA) are given.

EDX elemental maps combined with EDX elemental line scans on a single-particle level were conducted to validate the elemental distribution in the NPs (Figs. 2 and 3).

Accordingly, all elements (Cr, $\mathrm{Co}, \mathrm{Fe}, \mathrm{Ni}, \mathrm{Mn}$, and $\mathrm{Mo}$ ) present in the HEA bulk target were also found in all the analyzed NPs of different diameters, which indicates the formation of alloyed particles in all cases. The EDX signals in the elemental maps (Figs. 2(a) and 3(a)) of $\mathrm{Cr}, \mathrm{Co}, \mathrm{Fe}, \mathrm{Ni}$, and $\mathrm{Mn}$ show homogeneous distributions of each element within the NPs, which indicate the absence of elemental segregations on this scale for these elements. Therefore, we could exclude the formation of segregated NPs with different phases, that was observed in other multi-metallic material systems before [52]. However, when comparing the signal intensities of the different NPs, a partially deviating intensity is shown for the Mn and Mo maps, compared to the other elements, in the $\mathrm{Cr}_{16} \mathrm{Co}_{16} \mathrm{Fe}_{16} \mathrm{Ni}_{16} \mathrm{Mn}_{30} \mathrm{Mo}_{06} \mathrm{NPs}$ (Fig. 3(a)).

These signal intensities can be affected by various parameters such as the particle diameter, average atomic number, morphology, and chemical composition of the particles. Thereto, chemical compositions of single NPs were quantified by STEMEDX area measurements. These measurements also show partial deviations from the nominal chemical compositions (Table S2 in the ESM), especially Mn-rich or Mo-rich NPs were occasionally found where mostly only one of the two elements was enriched in the corresponding particles (Fig. S1 in the ESM). The discrepancy between the measured and nominal chemical compositions of the HEA NPs could be partially explained based on the surface compositions of the HEA ablation targets observed after their ablation. Although the EDX-maps show a homogeneous distribution of the desired elements on the target surface (Fig. S2 in the ESM), the averaged surface composition data from EDX and XRF analysis both show small deviations (Tables S3 and S4 in the ESM) from the nominal compositions, possibly mediated due to partial surface metal oxidations. The EDX elemental maps of Mn (green) also show an inhomogeneous lateral distribution with a signal arising around the NP surfaces (Fig. 2(a)), which indicates enrichment of $\mathrm{Mn}$ or the formation of a Mn-rich byproduct

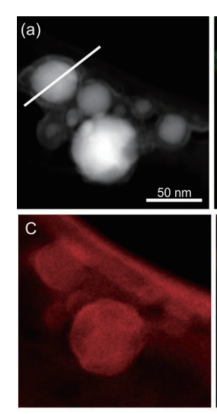

(b)

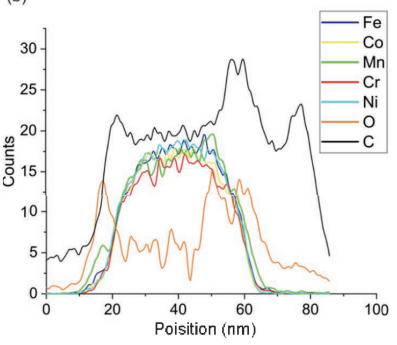

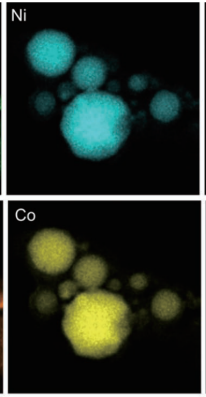
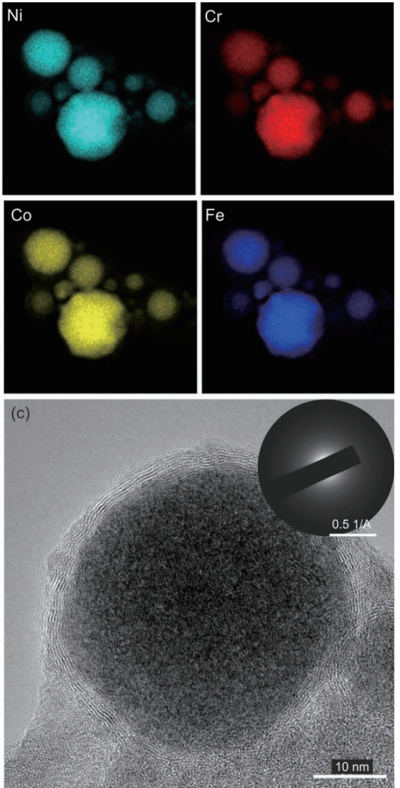

Figure 2 TEM characterization of the $\mathrm{Cr}_{17.5} \mathrm{Co}_{17.5} \mathrm{Fe}_{17.5} \mathrm{Ni}_{17.5} \mathrm{Mn}_{30}$ NPs. (a) HAADF-STEM image and EDX elemental maps of Mn, Ni, Cr, C, O, Co, and Fe. (b) EDX elemental line scan of the constituent elements (position is marked in (a)), (c) HRTEM micrograph, and (inset) SAED pattern.

outside the NPs. Next to Mn, the formation of an O outer layer on the NP surfaces is revealed by the EDX elemental maps of $\mathrm{O}$ (orange) regardless of Mo being present in the target (Figs. 2(a) and 3(a)). This seems to indicate partial oxidation of Mn next to the NP surfaces by the formation of $\mathrm{MnO}_{x}$. However, the oxidation of the NPs seems to be enhanced on the surfaces, which is illustrated by the weak $\mathrm{O}$ signal inside the NPs. EDX elemental line scans, depicted in Figs. 2(b) and 3(c), validate these assumptions by showing lower counts of the $\mathrm{O}$ signal inside the NPs, also in line with previous studies where surface atoms were oxidized during PLAL [68]. Furthermore, the $\mathrm{O}$ enrichment on the surface is validated by the respective signals of the elemental 

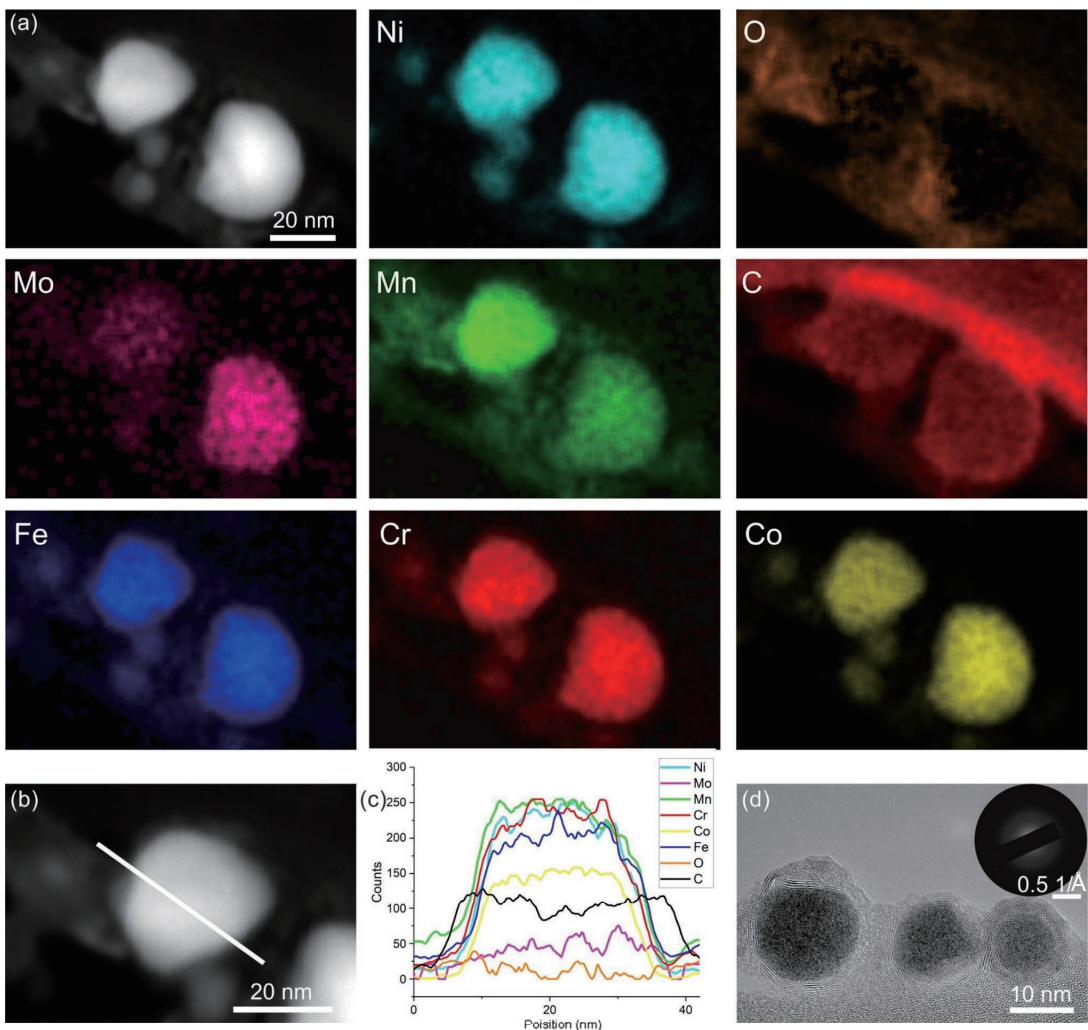

Figure 3 TEM characterization of the $\mathrm{Cr}_{16} \mathrm{Co}_{16} \mathrm{Fe}_{16} \mathrm{Ni}_{16} \mathrm{Mn}_{30} \mathrm{Mo}_{06}$ HEMG NPs. (a) HAADF-STEM image and EDX elemental maps of Ni, O, Mo, Mn, C, Fe, Cr, and Co. (b) Magnified HAADF-STEM image of the upper NP shown in (a), (c) EDX elemental line scan (position marked in (b)) of the respective elements and (d) HRTEM micrograph and (inset) SAED pattern.

line scans showing relatively stronger $\mathrm{O}$ signals on the NP surfaces and next to the NPs. Given the high oxygen solubility of acetonitrile and that acetonitrile molecules are free of oxygen, the emergence of the surface oxide layers could be mainly attributed to the dissolved oxygen and water in the surrounding medium [69]. Similarly, Marzun et al. concluded that active oxygen species, e.g., from the decomposition of water, are the main origin for oxidation after PLAL while dissolved oxygen promotes postablation oxidation processes [70]. In the example of porous FeCoNiCrNb HEA NPs, the presence of oxides on the NPs surface was found beneficial in promoting their catalytic OER activity due to their extraordinarily large surface area, and fast dynamics [71]. An additional oxygen source is the surface oxide layer that might be present in the bulk targets (Fig. S2 and Table $\mathrm{S} 3$ in the ESM).

The peak EDX elemental line scan signals of C (Figs. 2(b) and $3(\mathrm{c}))$ on the shells of the NPs indicate the formation of C-shells around the laser-generated NPs. The presence of a C-shell is further indicated by the HRTEM micrographs showing the formation of a thin $(\sim 2 \mathrm{~nm})$ layer around the NPs (Figs. 2(c) and $3(\mathrm{~d})$ ) and is well known for PLAL in organic solvents $[45,46$, 72-74]. Analysis by fast Fourier transform (Fig. S3 in the ESM) supports the formation of graphitic carbon shells with a measured lattice constant of $c=6.8 \AA$ for consecutive shells (literature value for graphite with space-group $P 6_{3} / m m c$ : $c=6.711 \AA$ ) [75]. These kinds of graphitic carbon layer formations were also shown for laser ablation of many single transition metal targets (e.g., Cr, Mo, $\mathrm{Ni}, \mathrm{Mn}$, and $\mathrm{Fe}$ ) in organic solvents [74]. It was also reported in the case of Pd [76], $\mathrm{Au}$ [77], and Ni [72] by different authors while the metal targets were ablated in acetonitrile. The formation mechanism of such a graphitic layer during the laser synthesis is still under debate. Choi et al. discussed that the sufficiently high temperature and pressure during laser ablation in acetonitrile leads to the production of $\mathrm{C}, \mathrm{H}$, and $\mathrm{N}$ ions and/or atoms together with $\mathrm{CH}_{3}$ and $\mathrm{CN}$ radicals [72]. These C-species condense onto the metal NP surfaces during the adiabatic cooling step thus generating a carbon layer around the HEA NPs. Reichenberger et al. on the other hand modeled the dependence of nanoparticle size and carbon shell thickness [72] assuming the initial homogeneous mixture of metal and carbon and found a very good agreement of model and experimental results [46]. Hence, while both interpretations provide potential boundary conditions, the exact mechanism still remains to be investigated. The catalytic influence of the transition metals in the HEA NPs might additionally favor the dynamic catalytic reactions thereby generating hydrogen gas and finally forming the graphitic shells $[72,78]$. These C-shells are favorable for the oxygen resistance of the NP core, thus constituting a barrier towards oxidation of the particles [79]. Please note that the line scans indicate the co-existence of $\mathrm{Mn}, \mathrm{O}$, and $\mathrm{C}$ in the shells. Hence it cannot be excluded that low amounts of manganese oxides and hydroxides are also present in the shells. Despite the graphitic shell formations, the absence of both the periodic arrangements in the HRTEM micrographs (Figs. 2(c) and $3(\mathrm{~d})$ ) and the Bragg reflection intensities on concentric rings in the SAED patterns (insets of Figs. 2(c) and 3(d)), acquired from regions containing a large number of NPs, imply the amorphous nature of the laser-generated NPs. In addition, the HRTEM micrographs and SAED patterns of the $\mathrm{Cr}_{14} \mathrm{Co}_{14} \mathrm{Fe}_{14} \mathrm{Ni}_{14} \mathrm{Mn}_{30} \mathrm{Mo}_{14}$ and $\mathrm{Cr}_{10} \mathrm{Co}_{10} \mathrm{Fe}_{10} \mathrm{Ni}_{10} \mathrm{Mn}_{30} \mathrm{Mo}_{30}$ NPs (Fig. S4 in the ESM) further confirm that the amorphous nature is preserved even after the incorporation of higher Mo contents. The high carbon signals on the NPs indicate possible incorporation of carbon into the NPs, but due to the superposition of the surrounding C-shell, the carbon support film (TEM grid), and the residuals of the acetonitrile solvent, further analytical methods exceeding the scope of this paper would be needed to unambiguously prove the presence of carbon inside the NPs. However, in accordance with previous studies, the incorporation of carbon into the HEA NPs could be expected due to the decomposition of the solvent molecules to form active C-species (atoms, ions, etc.) during the 
plasma phase, thus providing the platform for diffusion into the hot plume droplets from the laser ablation $[57,72,74,80]$. The carbon helps to retard the precipitation of the crystalline phases during NP formation and stabilizes the metallic liquid which increases the chance of amorphization in such a complex alloy system $[57,81,82]$. The amorphization behavior is expected to be further enhanced when the particles are enclosed in graphitic shells [83] where the dissolved carbon in high entropy alloy matrix with a single solid solution phase may facilitate the stabilization of an amorphous phase under a high quenching rate due to a more negative mixing enthalpy and a larger atomic size difference [84]. Interestingly, the current results are different from the pulsed laser ablation of a similar HEA in ethanol, where the generated NPs were crystallized into a single fcc phase [52]. Since acetonitrile contains a higher carbon:hydrogen ratio than ethanol [85], it provides a more carbon-enriched environment in the plume during ablation. Consequently, an enhanced carbon diffusion into the core and a higher simultaneous $\mathrm{C}$-shell formation rate during the ablation process can be expected to facilitate the amorphization of the HEMG NPs. A correlation of the C:H ratio of the solvents with the C-shell thickness was also previously proposed from a literature survey [46].

Given that amorphous structural features were observed in the single NPs in HRTEM and SAED for different high entropy systems on a limited number of particles, further confirmation of the ensemble structure is needed, especially on a large scale. We hence carried out powder XRD on laser-generated NPs of the alloy systems (Fig. 4). Mo-free $\mathrm{Cr}_{17.5} \mathrm{Co}_{17.5} \mathrm{Fe}_{17.5} \mathrm{Ni}_{17.5} \mathrm{Mn}_{30}$ HEMG NPs exhibit a combination of apparent broad diffuse diffraction reflections at $2 \theta$ regions of $30^{\circ}-70^{\circ}$, and some low-intensity peaks located on the broad hallows. This indicates that the NP ensemble is mainly composed of the amorphous structure (as indicated in the inset of Fig. 4(a)) together with a low fraction of single fcc structure with (111) and (200) planes at $42.9^{\circ}$ and $50.0^{\circ}$, respectively. The single fcc phase is in good agreement with a previous work of HEA NPs in ethanol [52], where the crystalline fcc phase was well noted by the high-intensity sharp reflection peaks. In contrast, as previously discussed in the context of the SAED patterns in Figs. 2(c) and 3(d), the majority of the HEMG NPs generated in acetonitrile exhibit a mostly amorphous structure. Simultaneously, the incorporation of 6 at.\% Mo contributes to a higher degree of NP amorphization with a lower intensity of the crystalline phase. The detection of the minor fcc phase only by XRD (not in HRTEM and SAED) led to the assumption that this crystalline part is originating from larger particles $(>50 \mathrm{~nm})$. The determined crystallite size $(10-20 \mathrm{~nm})$, however, points towards the polycrystalline nature of the larger NPs with domain sizes that are comparable to the mean size of the amorphous NPs obtained from TEM (Fig. 4(b)). To validate our assumption on larger particles contributing to the minor crystalline phase, we extracted smaller $(<50 \mathrm{~nm})$ NPs from the $\mathrm{Cr}_{16} \mathrm{Co}_{16} \mathrm{Fe}_{16} \mathrm{Ni}_{16} \mathrm{Mn}_{30} \mathrm{Mo}_{06}$ sample by centrifugation and again performed XRD on the particles in the supernatant (Fig. S5 in the ESM). It was shown that the reflections of the fcc structure were not present confirming that the fcc phase mainly originates from the larger NPs. It should be noted that, although most of the NPs constitute the amorphous phase, the detection of the fcc fraction was still beneficial for confirming the Mo incorporation in the $\mathrm{Cr}_{17.5} \mathrm{Co}_{17.5} \mathrm{Fe}_{17.5} \mathrm{Ni}_{17.5} \mathrm{Mn}_{30}$ lattice. Since the atomic radius of $\mathrm{Mo}$ $(0.139 \mathrm{~nm})$ is much larger than those of Fe $(0.126 \mathrm{~nm})$, Co $(0.125$ $\mathrm{nm}), \mathrm{Ni}(0.124 \mathrm{~nm}), \mathrm{Cr}(0.128 \mathrm{~nm})$, and $\mathrm{Mn}(0.127 \mathrm{~nm})$, the atomic substitution must be accompanied with an increase in the unit cell parameter and interplanar spacing, as shown in Fig. 4(b) and Fig. S6 in the ESM, respectively. Such an observation leads to the assumption that the amorphous HEA NPs should also follow
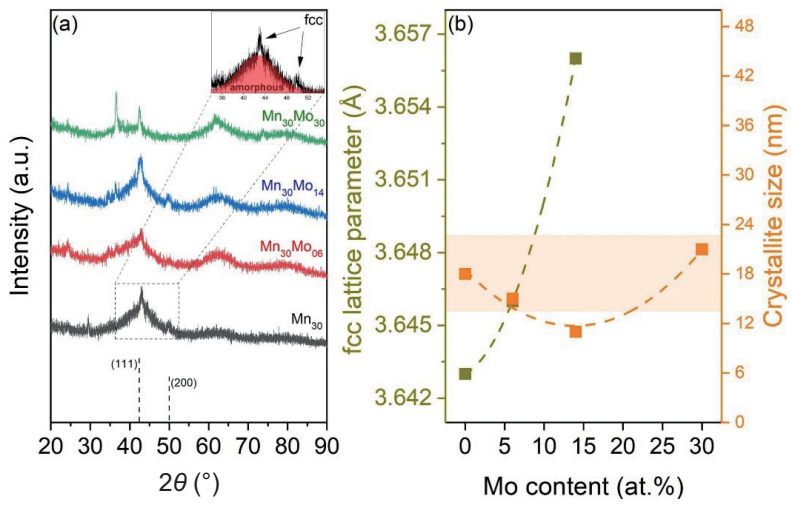

Figure 4 (a) XRD diffractograms of $\mathrm{Cr}_{17.5} \mathrm{Co}_{17.5} \mathrm{Fe}_{17.5} \mathrm{Ni}_{17.5} \mathrm{Mn}_{30}, \mathrm{Cr}_{16} \mathrm{Co}_{16} \mathrm{Fe}_{16}$ $\mathrm{Ni}_{16} \mathrm{Mn}_{30} \mathrm{Mo}_{06}, \mathrm{Cr}_{14} \mathrm{Co}_{14} \mathrm{Fe}_{14} \mathrm{Ni}_{14} \mathrm{Mn}_{30} \mathrm{Mo}_{14}$, and $\mathrm{Cr}_{10} \mathrm{Co}_{10} \mathrm{Fe}_{10} \mathrm{Ni}_{10} \mathrm{Mn}_{30} \mathrm{Mo}_{30} \mathrm{NPs}$ showing the (mostly) amorphous structure. The inset of (a) shows the large abundance of the amorphous phase (red shaded region) as well as a small contribution from the crystalline fcc phase separately for the representative $\mathrm{Cr}_{17.5} \mathrm{Co}_{17.5} \mathrm{Fe}_{17.5} \mathrm{Ni}_{17.5} \mathrm{Mn}_{30}$ sample. (b) Lattice parameters corresponding to the $\mathrm{fcc}$ phase showing more incorporation of Mo into the lattice with increasing Mo content and the crystallite sizes in the similar region of the particles sizes (yellow shaded region).

the same trend of increasing Mo as the minor crystalline fraction. At the same time, further addition of Mo (14 at.\% and 30 at.\%) leads to the formation of different intermetallic phases in addition to the fcc phase, as one can assume from the binary phase diagrams, e.g., Ni-Mo [86] and Fe-Mo [87]. Due to the higher number of constituents, the probability for such intermetallic phase formations would be even higher in the HEA system which may affect the resulting electrochemical properties. Supporting this assumption, our XRD measurements indicated appearances of additional weak reflection intensities with increasing Mo content, as well denoted by the reflection at $2 \theta$ of $36.5^{\circ}$, especially for the $\mathrm{Cr}_{10} \mathrm{Co}_{10} \mathrm{Fe}_{10} \mathrm{Ni}_{10} \mathrm{Mn}_{30} \mathrm{Mo}_{30}$ NPs. The $\mathrm{Cr}_{10} \mathrm{Co}_{10} \mathrm{Fe}_{10}$ $\mathrm{Ni}_{10} \mathrm{Mn}_{30} \mathrm{Mo}_{30}$ NPs are characterized by a higher degree of crystallinity compared to the lower Mo compositions, where the reflections at $2 \theta$ values of $36.5^{\circ}$ and $42.4^{\circ}$ might be assigned to the substituted Ni-Mo-based intermetallic phase (ICDD \#50-1270), while no fcc phase is detected. The larger fraction of the amorphous phase at least in the $\mathrm{Cr}_{17.5} \mathrm{Co}_{17.5} \mathrm{Fe}_{17.5} \mathrm{Ni}_{17.5} \mathrm{Mn}_{30}$, $\mathrm{Cr}_{16} \mathrm{Co}_{16} \mathrm{Fe}_{16} \mathrm{Ni}_{16} \mathrm{Mn}_{30} \mathrm{Mo}_{06}$, and $\mathrm{Cr}_{14} \mathrm{Co}_{14} \mathrm{Fe}_{14} \mathrm{Ni}_{14} \mathrm{Mn}_{30} \mathrm{Mo}_{14}$ compositions are expected to contribute to better catalytic properties in water oxidation due to the enhanced density of coordinately unsaturated sites and metastable state with higher Gibbs free energy in the amorphous structure $[88,89]$. However, they might differ in their electrochemical performance in terms of the increasing contribution of the minor intermetallic phases. The amorphization of the HEA NPs, in this case, could be mainly attributed to the solvent (acetonitrile) which acts as the carbon source. Diffusion of carbon atoms into the metallic matrix depends on their affinity and enthalpy to form metal-carbon bonds and significantly increases the mobility of the metallic liquid, thereby promoting the NP's amorphization ability during the quenching process [57]. A confinement effect of the C-shell can also be expected here thereby suppressing the recrystallization and stabilizing the amorphous structure of the metallic cores [57]. In contrast, when using solvents with a lower tendency for graphitization, such as ethanol which was used by Waag et al., the effect of such carbon diffusion, as well as the graphitic layer formation, is less pronounced such that HEA NPs with more pronounced crystalline structures were gained [52].

In addition to the structural information, analysis of the surface chemical states of the HEMG NPs is important, especially to reveal the structure-property relation in the catalytic application as catalysis mainly occurs at the surface of the particles. Thereto, 
high-resolution XPS studies were performed for analyzing the dominant elements in HEMG NPs and shown for the representative $\mathrm{Cr}_{16} \mathrm{Co}_{16} \mathrm{Fe}_{16} \mathrm{Ni}_{16} \mathrm{Mn}_{30} \mathrm{Mo}_{06}$ composition in Fig. 5. Obviously, all metal elements except $\mathrm{Mn}$ contain the significant fraction at elemental state (zero-valent state), i.e., $\mathrm{Cr} 2 \mathrm{p}_{3 / 2}$ at 574.2 $\mathrm{eV}$, Co $2 \mathrm{p}_{3 / 2}$ at $778.2 \mathrm{eV}, \mathrm{Fe} 2 \mathrm{p}_{3 / 2}$ at $707.5 \mathrm{eV}, \mathrm{Ni} 2 \mathrm{p}_{3 / 2}$ at $852.9 \mathrm{eV}$, and $\mathrm{Mo} 3 \mathrm{~d}_{5 / 2}$ at $228.1 \mathrm{eV}$, agreeing well with the binding energy values reported for the amorphous structure [90]. According to the STEM-EDX results in Fig. 3, O was found in the NP shell, thus leading to the generation of surface metal oxides/hydroxides, where they are supported by the detection of $\mathrm{Cr}^{3+}$ at $576.6 \mathrm{eV}(\mathrm{Cr}$ $\left.2 \mathrm{p}_{3 / 2}\right), \quad \mathrm{Co}^{2+} / \mathrm{Co}^{3+}$ at $779.9-781.6 \mathrm{eV}\left(\mathrm{Co} 2 \mathrm{p}_{3 / 2}\right), \mathrm{Fe}^{2+} / \mathrm{Fe}^{3+}$ at $710.1-711.6 \mathrm{eV}\left(\mathrm{Fe} 2 \mathrm{p}_{3 / 2}\right), \mathrm{Ni}^{2+}$ at $854.0 \mathrm{eV}\left(\mathrm{Ni} 2 \mathrm{p}_{3 / 2}\right)$, and $\mathrm{Mo}^{4+}$ at $228.9 \mathrm{eV}$, which coincide with the lattice oxygen $\mathrm{O}^{2-}$ in the form of metal-oxygen bonds shown in the $\mathrm{O} 1 \mathrm{~s}$ high-resolution XPS spectrum (Fig. 5). Note that the main bonding of $\mathrm{O}$ at $532 \mathrm{eV}$ comes from the $\mathrm{C}-\mathrm{O}$ as shown in the $\mathrm{C} 1 \mathrm{~s}$ spectrum, but the dominant component of the shell structure originates from the graphitic C-enriched with $\mathrm{C}-\mathrm{C}$, which also agrees with our observation in HRTEM (Fig. 3(d)). Also, our assumptions that (I) the shell contains small amounts of metal hydroxides, primarily manganese as it is most strongly oxidized and (II) that the graphite shell is partially oxidized (C-O bonds), are confirmed by XPS. The enrichment of carbon in the shell and potentially also the bulk nanoparticle structure as discussed earlier indeed plays a significant role in the formation of the amorphous structure in the high entropy system due to the confinement effect thus suppressing the heterogeneous recrystallization and stabilizing the amorphous structure $[57,83]$. By analyzing the XPS spectra, one can assume that the laser-generated HEMG NPs are mainly composed of C-shell (dissolved with minor metal oxides and carbon oxides) on the surface and zero-valent metals in the core. In addition, Fig. 6 compares the nominal compositions (at.\%) of different HEMG NPs with the surface compositions measured from the high-resolution XPS spectra, where $\mathrm{Cr}, \mathrm{Ni}, \mathrm{Fe}$, and $\mathrm{Co}$ show preservation of the nominal composition on the surface of the NPs after ablation. However, surfaces enriched by Mn are found and the surface composition of Mo in the NPs is always lower than the nominal composition. Based on the Mn enrichment on the surface of the as-synthesized HEMG NPs shown by the STEM-EDX results, it can be assumed that the surface of the HEMG NPs contains a higher fraction of Mn oxides. The formation of oxides of Mn rather than other elements in the cantor alloy can be expected due to the more negative Gibb's free energy of formation of the Mn-oxides [91]. For instance, Douglass et al. observed $\mathrm{Mn}_{2} \mathrm{O}_{3}$ surface layer formations for a Fe$\mathrm{Mn}-\mathrm{Cr}-\mathrm{Ni}-\mathrm{C}-\mathrm{N}$ austenitic alloy which resulted in the selective removal of $\mathrm{Mn}$ from the alloy phase $[92,93]$. Based on the characterization methods discussed above, the HEMG NPs generated here are constituting a structure that is enclosed in thin graphitic shells. Further, we can assume that some C-species are incorporated inside the metallic core depending on the affinity towards different transition metals.

After identifying the morphology, elemental distribution, amorphous structure, and surface oxidation states, we will now turn to the electrochemical application of the HEMG NPs. In general, the different neighboring atomic environments and the presence of several adsorption sites due to the multiple elements make HEA NPs highly attractive for catalysis [12]. Moreover, the noble metal-free HEA NPs also possess an additional advantage of
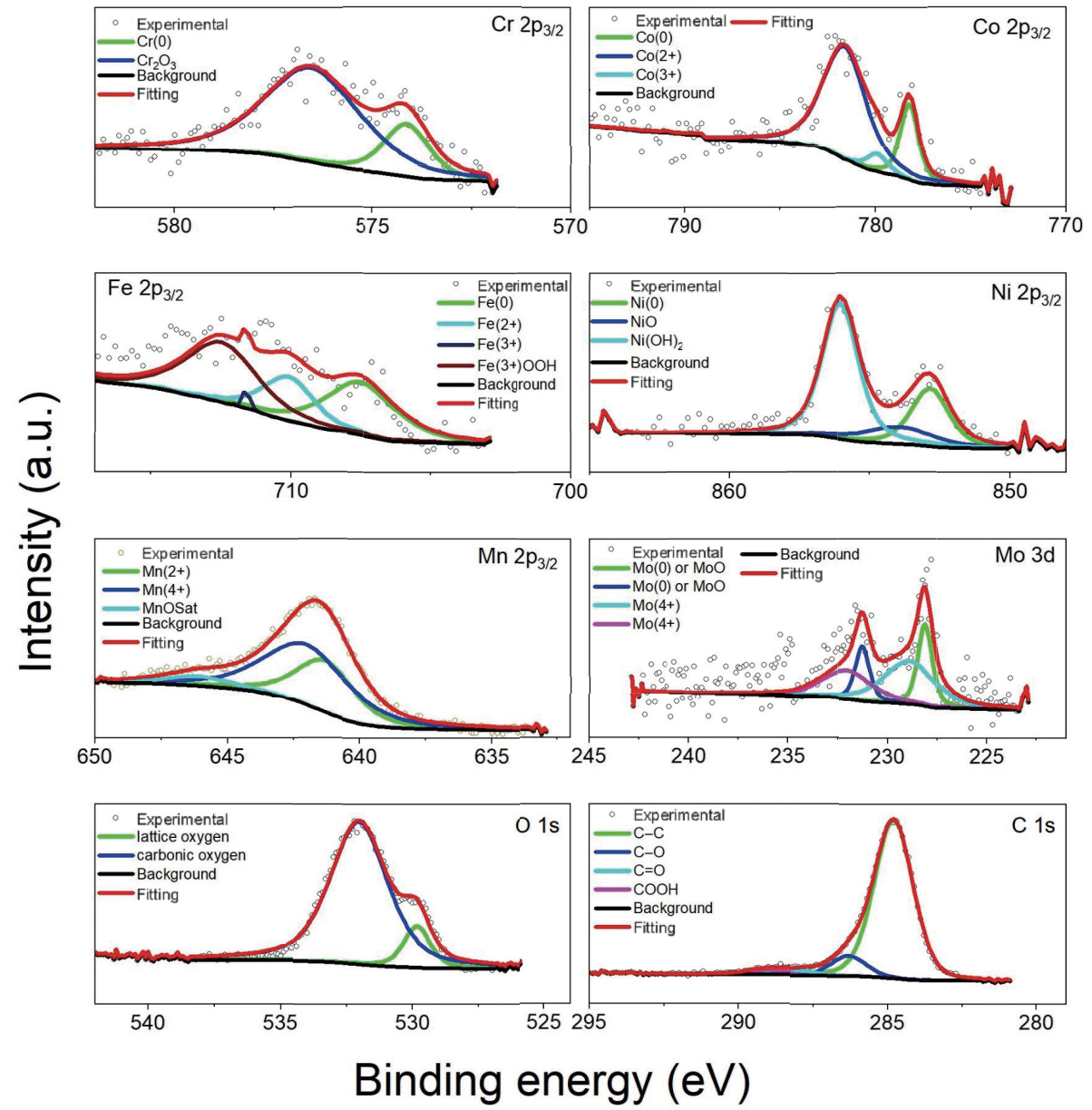

Figure 5 Representative XPS high resolution spectra of $\mathrm{Cr} 2 \mathrm{p}_{3 / 2}$, Co 2 $\mathrm{p}_{3 / 2}, \mathrm{Fe} 2 \mathrm{p}_{3 / 2}, \mathrm{Ni} 2 \mathrm{p}_{3 / 2}, \mathrm{Mn} 2 \mathrm{p}_{3 / 2}$, Mo $3 \mathrm{~d}$, O 1s, and C 1s corresponding to the $\mathrm{Cr}_{16} \mathrm{Co}_{16} \mathrm{Fe}_{16}$ $\mathrm{Ni}_{16} \mathrm{Mn}_{30} \mathrm{Mo}_{06} \mathrm{NPs}$. 


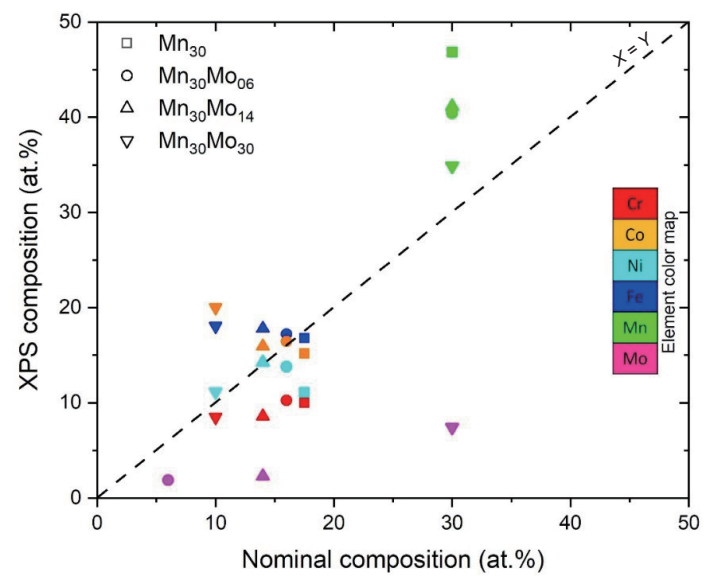

Figure 6 XPS surface composition of all elements in the HEMG NPs vs. the nominal target composition for $\mathrm{Cr}_{17.5} \mathrm{Co}_{17.5} \mathrm{Fe}_{17.5} \mathrm{Ni}_{17.5} \mathrm{Mn}_{30}, \mathrm{Cr}_{16} \mathrm{Co}_{16} \mathrm{Fe}_{16} \mathrm{Ni}_{16} \mathrm{Mn}_{30}$ $\mathrm{Mo}_{06}, \mathrm{Cr}_{14} \mathrm{Co}_{14} \mathrm{Fe}_{14} \mathrm{Ni}_{14} \mathrm{Mn}_{30} \mathrm{Mo}_{14}$, and $\mathrm{Cr}_{10} \mathrm{Co}_{10} \mathrm{Fe}_{10} \mathrm{Ni}_{10} \mathrm{Mn}_{30} \mathrm{Mo}_{30}$ compositions.

cost-effectiveness for industry-level catalysis applications where large quantities of NPs are required [94]. Since the HEA NPs have been widely employed as electrocatalysts for OER and ORR, we also tested the potential of the laser-generated HEMG NPs of different compositions for these catalytic reactions (Fig. 7 and Fig. S7 in the ESM).

The OER tests were performed in an alkaline $(0.1 \mathrm{M} \mathrm{NaOH})$ electrolyte employing the HEMG NPs supported on carbon black as the working electrode in a three-electrode potentiostat (see the experimental section for details). The OER performance of the HEMG NPs of different compositions is presented in Figs. 7(a) and 7(b). A composition-dependent trend on the OER performance of the HEMG NPs can be directly seen from the differing overpotentials and current densities plotted in Fig. 7(b) vs. the nominal Mo content. Note that, in Fig. 7(b), the current density values at an overpotential of $0.47 \mathrm{~V}$ and the overpotentials at a current density of $6 \mathrm{~mA} / \mathrm{cm}^{2}$ are shown for each sample for easy comparison. The current density values were obtained by normalizing the measured currents using the geometrical area of the glassy carbon electrode. Since the electrode area was covered using a constant mass of the catalyst (i.e., the same mass of the HEMG NPs) in each case, the results are directly comparable and an effect of the mass of the material can be excluded. The $\mathrm{Cr}_{16} \mathrm{Co}_{16} \mathrm{Fe}_{16} \mathrm{Ni}_{16} \mathrm{Mn}_{30} \mathrm{Mo}_{06}$ HEMG NPs show the highest activity with a current density of $\sim 12.3 \mathrm{~mA} / \mathrm{cm}_{\text {geo }}{ }^{2}$ at an overpotential of $0.47 \mathrm{~V}$ among the four tested compositions while the particles containing 30 at.\% Mo present the lowest OER activity $(\sim 9.8$ $\mathrm{mA} / \mathrm{cm}_{\text {geo }}{ }^{2}$ at $\left.0.47 \mathrm{~V}\right)$. This indicates that the addition of a small amount $(\sim 6$ at.\%) of Mo into the cantor alloy enhances the OER activity while further Mo addition has a gradual negative impact. The higher OER activity of the $\mathrm{Cr}_{16} \mathrm{Co}_{16} \mathrm{Fe}_{16} \mathrm{Ni}_{16} \mathrm{Mn}_{30} \mathrm{Mo}_{06}$ HEMG NPs could be attributed to the slightly increased interplanar distance in the amorphous phase due to the incorporated larger Mo atoms compared to the cantor alloy NPs [95]. Such lattice distortions can drive HEAs into nonequilibrium thermodynamic states leading to lower potential energies and in turn lower energy barriers during the catalytic processes [96]. But $\mathrm{Cr}_{14} \mathrm{Co}_{14} \mathrm{Fe}_{14}$ $\mathrm{Ni}_{14} \mathrm{Mn}_{30} \mathrm{Mo}_{14}$ NPs show lower activities possibly due to the presence of more crystalline intermetallic phases as also shown by XRD (Fig. 4), especially for the $\mathrm{Cr}_{10} \mathrm{Co}_{10} \mathrm{Fe}_{10} \mathrm{Ni}_{10} \mathrm{Mn}_{30} \mathrm{Mo}_{30}$ NPs with the lowest OER activity. Tafel slopes acquired for the different compositions also show the higher and lower efficiencies of the $\mathrm{Cr}_{16} \mathrm{Co}_{16} \mathrm{Fe}_{16} \mathrm{Ni}_{16} \mathrm{Mn}_{30} \mathrm{Mo}_{06}$ and $\mathrm{Cr}_{10} \mathrm{Co}_{10} \mathrm{Fe}_{10} \mathrm{Ni}_{10} \mathrm{Mn}_{30} \mathrm{Mo}_{30}$ NPs, with Tafel slopes of 93 and $100 \mathrm{mV} / \mathrm{dec}$, respectively (Fig. S8(a) in the ESM). Here, it should be noted that the electrocatalytic performance depends heavily on the specific surface activity, which is influenced by the surface defects in the particles. Thus, the amorphous nature of the HEA NPs generated here is highly relevant as such structures always possess denser distribution of defects, a higher concentration of coordinatively unsaturated sites, higher potential energy, and more loosely bonded atoms [22, 36, 37]. It is known that the smaller particles usually present better catalytic activity due to their increased surface area for a constant mass. However, in our case, particle size is not the ruling factor as the $\mathrm{Cr}_{17.5} \mathrm{Co}_{17.5} \mathrm{Fe}_{17.5} \mathrm{Ni}_{17.5} \mathrm{Mn}_{30}$ and $\mathrm{Cr}_{14} \mathrm{Co}_{14} \mathrm{Fe}_{14} \mathrm{Ni}_{14} \mathrm{Mn}_{30} \mathrm{Mo}_{14}$ HEMG NPs show different OER activities despite their comparable mean particle size $(\sim 22 \mathrm{~nm}$, Fig. 1$)$. In fact, although all HEMG compositions show a broad size distribution, the specific surface areas of the samples were comparable (see Fig. 1) such that the catalytic activity appears to be more dominantly affected by compositional effects rather than size effects.

To evaluate the performance of our HEMG NPs-based catalysts, the obtained current densities and overpotentials should be compared with those reported in the literature. However, the different approaches adopted in the catalyst preparations together with the variations in the measurements (e.g., different electrolyte concentrations) often make a direct comparison challenging. Therefore, we compared the OER activity of the HEMG NPs obtained here to that reported recently for laser-generated CrCoFeNiMn HEA NPs in ethanol where the measurements and the preparation of the catalysts were similar [52]. In that case, the current densities were normalized to the total mass of the HEA NPs, and the $\mathrm{Cr}_{20} \mathrm{Co}_{20} \mathrm{Fe}_{20} \mathrm{Ni}_{20} \mathrm{Mn}_{20}$ HEA NPs generated in ethanol showed a current density of $\sim 0.6 \mathrm{~A} / \mathrm{mg}$ at a potential of $1.7 \mathrm{~V}$. This current density is much lower compared to the present study $(\sim 1 \mathrm{~A} / \mathrm{mg})$ even accounting the small difference in the composition (20 at.\% equiatomic composition vs. $\mathrm{Cr}_{17.5} \mathrm{Co}_{17.5} \mathrm{Fe}_{17.5}$ $\mathrm{Ni}_{17.5} \mathrm{Mn}_{30}$ in the literature and the current work, respectively). It is also worth noting that the crystalline HEA NPs generated in ethanol show a lower average diameter $(<10 \mathrm{~nm})$ [52] and hence possess higher specific surface areas compared to the current study. Furthermore, when 6 at.\% Mo is incorporated into the CrCoFeNiMn, the current density at $1.7 \mathrm{~V}$ is further increased to $1.2 \mathrm{~A} / \mathrm{mg}$, twice as the current density value of the cantor HEA NPs bearing an equiatomic composition produced in ethanol [52]. Besides this, the HEMG NPs-based electrocatalysts are stable in the given alkaline medium where only small deviations in the measured current are noted over 10 consecutive cycles (Fig. S9 in the ESM). Vassalini et al. reported the catalytic performance of the $\mathrm{Au}-\mathrm{Fe}$ NPs obtained from laser ablation in liquid [97]. In that case, the highest activity was found for the $\mathrm{Au}_{89} \mathrm{Fe}_{11}$ composition with an overpotential of $\sim 0.8 \mathrm{~V}$ at $10 \mathrm{~mA} / \mathrm{cm}^{2}$. All the HEMG NPs generated in the current work, irrespective of their composition, outperform these Au-Fe bimetallic alloy NPs where the $\mathrm{Cr}_{16} \mathrm{Co}_{16} \mathrm{Fe}_{16} \mathrm{Ni}_{16} \mathrm{Mn}_{30} \mathrm{Mo}_{06} \mathrm{NPs}$ achieve a current density of 10 $\mathrm{mA} / \mathrm{cm}^{2}$ at an overpotential as low as $\sim 0.4 \mathrm{~V}$. However, it should be noted that the current OER tests were done in $0.1 \mathrm{M} \mathrm{NaOH}$ while Vassalini and co-workers performed the tests in $1 \mathrm{M} \mathrm{KOH}$ solution. In another work, Marzun et al. tested the OER activity of laser-generated Ni-Mo alloy NPs where they exhibited a current density of only $\sim 7 \mathrm{~mA} / \mathrm{cm}^{2}$ at $0.75 \mathrm{~V}$ even after 150 cycles [98]. The catalysts based on the HEMG NPs generated here also possess higher OER activities in comparison to the activities of $\mathrm{Co}_{3} \mathrm{O}_{4^{-}}$ based catalysts [99] as well as laser-generated Co-Ni NPs [52] of different compositions.

To further demonstrate the applicability of the HEMG NPs in heterogeneous catalysis, we tested the ORR activities of HEMG/C catalysts (Figs. 7(c) and 7(d)) as it is highly relevant in energy conversion systems such as fuel cells [100]. In contrast to the OER activities, here the $\mathrm{Cr}_{17.5} \mathrm{Co}_{17.5} \mathrm{Fe}_{17.5} \mathrm{Ni}_{17.5} \mathrm{Mn}_{30}$ and $\mathrm{Cr}_{14} \mathrm{Co}_{14} \mathrm{Fe}_{14}$ $\mathrm{Ni}_{14} \mathrm{Mn}_{30} \mathrm{Mo}_{14} \mathrm{NPs}$ show better activities as characterized by lower 

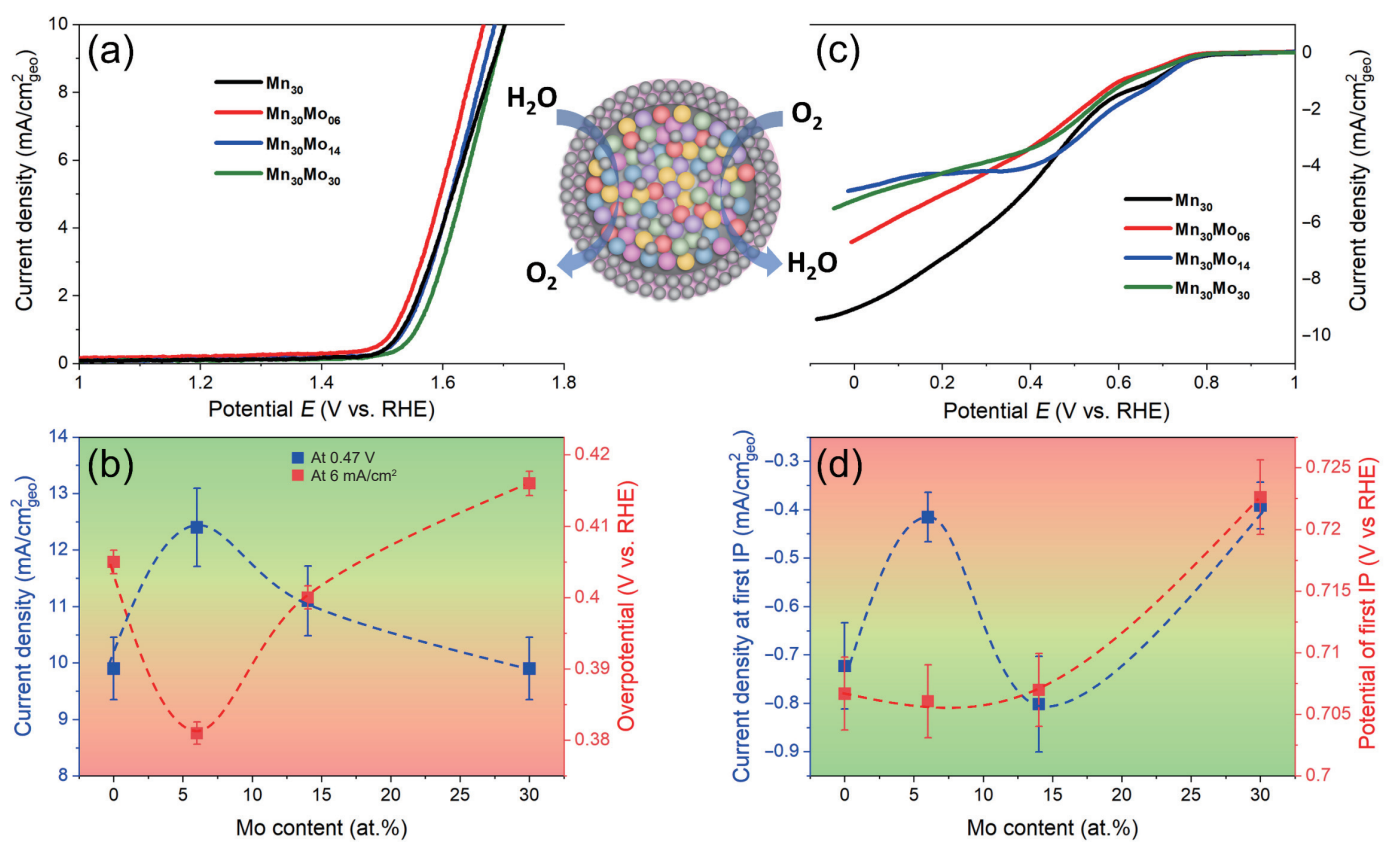

Figure 7 (a) OER LSV curves of $\mathrm{Cr}_{17.5} \mathrm{Co}_{17.5} \mathrm{Fe}_{17.5} \mathrm{Ni}_{17.5} \mathrm{Mn}_{30}, \mathrm{Cr}_{16} \mathrm{Co}_{16} \mathrm{Fe}_{16} \mathrm{Ni}_{16} \mathrm{Mn}_{30} \mathrm{Mo}_{06}, \mathrm{Cr}_{14} \mathrm{Co}_{14} \mathrm{Fe}_{14} \mathrm{Ni}_{14} \mathrm{Mn}_{30} \mathrm{Mo}_{14}$, and $\mathrm{Cr}_{10} \mathrm{Co}_{10} \mathrm{Fe}_{10} \mathrm{Ni}_{10} \mathrm{Mn}_{30} \mathrm{Mo}_{30} \mathrm{NPs}$ in $0.1 \mathrm{M}$ $\mathrm{NaOH}$ and (b) current density at an overpotential of $0.47 \mathrm{~V}$ and overpotential at a current density of $6 \mathrm{~mA} / \mathrm{cm}^{2}$ vs. the Mo content. (c) ORR LSV curves of the HEMG NPs and (d) current density and overpotential of different samples at the first IP. The dotted lines in (b) and (d) are for guiding the eye in following the trends. The green and red regions in (b) and (d) represent regions of higher and lower activities, respectively, based on the current densities. The error bars in (b) and (d) were calculated by repeating the OER and ORR tests of the $\mathrm{Cr}_{16} \mathrm{Co}_{16} \mathrm{Fe}_{16} \mathrm{Ni}_{16} \mathrm{Mn}_{30} \mathrm{Mo}_{06} \mathrm{NPs}$ three times and considering the relative error in other compositions.

negative current densities at a given overpotential. The ORR LSV curves are constituted by different current waves as shown in Fig. 7(c). Hence, to differentiate between these current waves and quantitatively compare the activities, we employed inflection point (IP) analysis. Recently, IP analysis was pioneered by Schuhmann et al. for laser-generated CrCoFeNiMn CSS NPs for comparing their composition-dependent ORR activity [35]. For the IP analysis, the raw LSV curves were fitted with different polynomial functions at respective intervals of the potentials where the curves show different trends. Derivatives of such fittings indicated the overpotential values at which maximum current densities are achieved. Figure $7(\mathrm{~d})$ shows the current densities and the overpotentials obtained from the first IP as a function of the Mo content. In analogy to the LSV curves in Fig. 7(c), it is found that the $\mathrm{Cr}_{14} \mathrm{Co}_{14} \mathrm{Fe}_{14} \mathrm{Ni}_{14} \mathrm{Mn}_{30} \mathrm{Mo}_{14}$ NPs show the highest negative current density $\left(\sim-0.8 \mathrm{~mA} / \mathrm{cm}_{\text {geo }}{ }^{2}\right)$ at an overpotential of $\sim 0.708$ $\mathrm{V}$ for the first IP. Although the $\mathrm{Cr}_{16} \mathrm{Co}_{16} \mathrm{Fe}_{16} \mathrm{Ni}_{16} \mathrm{Mn}_{30} \mathrm{Mo}_{06} \mathrm{NPs}$ show comparable overpotential at this point, the negative current density is much lower $\left(\sim-0.42 \mathrm{~mA} / \mathrm{cm}_{\text {geo }}{ }^{2}\right)$, indicating a lower density of the respective surface sites that are already active at this potential in case only $6 \%$ of Mo was present. Hu et al. produced $\mathrm{PtCo} / \mathrm{CoO}_{x}$ nanocomposites via laser ablation and employed them as catalysts for both OER and ORR [101]. The highest ORR activity was obtained for the PtCo sample having Pt:Co ratio 1:2 with a potential of $870 \mathrm{mV}$. This value is better than the current work, however, this can be attributed to the presence of expensive $\mathrm{Pt}$ in the samples with platinum-based catalysts still being the best ORR catalysts to date. Laser-generated PdY NPs also show better ORR activity than the HEMG NPs here due to the higher activity associated with $\mathrm{Pd}$ [102].

Interestingly, the $\mathrm{Cr}_{10} \mathrm{Co}_{10} \mathrm{Fe}_{10} \mathrm{Ni}_{10} \mathrm{Mn}_{30} \mathrm{Mo}_{30}$ NPs present the lowest activity at the $1^{\text {st }}$ IP during ORR as well as in OER. It is noteworthy that in this composition, in addition to the higher degree of crystallinity (denoted by high-intensity diffraction peaks in Fig. 4), the molar fractions of both Mn and Mo (30 at.\%) are explicitly high compared to other elements (10 at.\% each) in the system thus placing it far away from the conventional equiatomic HEA composition. Hence, this points to the hypothesis that either the absence/depletion of the other elements on the surface or the reduced configurational entropy in the system might have also been detrimental to the density of the most active surface sites [12]. The $\mathrm{Cr}_{10} \mathrm{Co}_{10} \mathrm{Fe}_{10} \mathrm{Ni}_{10} \mathrm{Mn}_{30} \mathrm{Mo}_{30}$ NPs yet continue to follow the same trend showing the lowest ORR activity during the second IP as well (Fig. S6(b) in the ESM). However, at the $2^{\text {nd }}$ IP or in other words, the $2^{\text {nd }}$ set of active sites at about $0.4 \mathrm{~V}$ higher overpotential (compared to the $1^{\text {st }} \mathrm{IP}$ ), the CrCoFeNiMn cantor HEMG NPs outperform the other compositions as also visible from the corresponding LSV curves at lower potentials with higher negative current density values. Accordingly, also the $\mathrm{Cr}_{16} \mathrm{Co}_{16} \mathrm{Fe}_{16} \mathrm{Ni}_{16} \mathrm{Mn}_{30} \mathrm{Mo}_{06}$ NPs exhibit a lower overpotential compared to that of the $\mathrm{Cr}_{14} \mathrm{Co}_{14} \mathrm{Fe}_{14} \mathrm{Ni}_{14} \mathrm{Mn}_{30} \mathrm{Mo}_{14} \mathrm{NPs}$ at the $2^{\text {nd }}$ IP (Fig. S8(b) in the ESM). Even though more IPs from other less active sites could be extracted, it is not feasible due to the higher overpotentials. Overall, for the $1^{\text {st }}$ IP that is most favorable for future applications due to its lowest overpotential, most active sites seem to form in the case of $\mathrm{Cr}_{14} \mathrm{Co}_{14} \mathrm{Fe}_{14} \mathrm{Ni}_{14} \mathrm{Mn}_{30} \mathrm{Mo}_{14}$ which hence provides a good platform to identify their true nature in future studies on alkaline ORR.

In short, laser-generated colloidal HEMG NPs with respective compositions show reliable activities towards OER and ORR. It can be assumed that the abundance of the amorphous phase, presence of the different metallic elements, lattice distortion, high entropy effects, graphitic shells, particle size, and different adsorption sites all influence the final catalytic activities of these HEMG NPs $[2,12,15,16]$.

Although the graphitic shells may limit access to the metal atoms during the catalytic reactions, the highly oxidizing conditions in OER are likely to oxidize the carbon next to the metallic components leading to corrosion of the carbon $[103,104]$. The detected redox peaks in the cyclic voltammograms are a very good indication that the metal atoms take part in the catalytic reactions during the potential scans also under ORR conditions (Figs. S7 and S8 in the ESM). Particularly a nitrogen doping of carbon which is likely in the case of carbon shells forming from nitrogen-containing acetonitrile has been shown to facilitate water diffusion through porous carbon [105]. Hence, a direct contact 
between the surface atoms of the HEMG NPs and the electrolyte from carbon corrosion or directly through the nm-thick carbon shell appears to render the latter still active in OER and ORR, respectively. It is also known that, due to the extremely fast initial cooling rates associated with PLAL [54], the generated NPs can possess defect-rich surfaces and metastable phases [106] which in turn impact their electrochemical properties $[58,73,107]$. In addition, since the catalytic reactions occur at the particle surface, the surface compositions of the HEMG NPs must be also seriously considered, especially when the surfaces are partially occupied by different intermetallic phases. For instance, some HEMG NPs in the present study showed an Mn-oxide-rich surface irrespective of the composition which can have a direct influence on the catalytic activities [108]. According to the catalytic measurements conducted, we find that the addition of a small amount ( 6 at.\%) of Mo into the CrCoFeNiMn system enhances the OER performance, while the incorporation of $\sim 14$ at. $\%$ Mo seems to improve the ORR activity of the HEMG NPs. Interestingly, the $\mathrm{Cr}_{10} \mathrm{Co}_{10} \mathrm{Fe}_{10} \mathrm{Ni}_{10} \mathrm{Mn}_{30} \mathrm{Mo}_{30}$ NPs, which are constituted by more crystalline phases, present the lowest activity in both ORR and OER. This underlines the promising impacts of the amorphous nature as well as the lattice distortion and entropy effects induced by the fractional addition of Mo in the CrCoFeNiMnMo HEMG NPs in catalysis.

\section{Conclusions}

In summary, we demonstrated the generation of quinary $\mathrm{CrCoFeNiMn}$ and senary CrCoFeNiMnMo HEMG NPs through pulsed laser ablation of the respective bulk targets in acetonitrile. We utilized acetonitrile not only as the solvent during ablation but also as the carbon source thus the generated particles probably contain some internalized C-species next to thin graphitic shells. Such C-related formations stabilized the HEAs with amorphous phases and resulted in the formation of the metallic glass structures on the nanoscale. By employing complementary HAADF-STEM, EDX, SAED, powder XRD, and XPS, the formation of the HEA NPs without the occurrence of significant segregation of single elements from the metallic glass structure was verified. The degree of amorphization was further influenced by the addition of different molar fractions of Mo into the $\mathrm{CrCoFeNiMn}$ matrix enabling larger atomic size mismatches. The generated HEA NPs were finally used as bifunctional electrocatalysts in OER and ORR as a function of incorporated Mo, and the obtained results were discussed in terms of the structure, elemental distribution, and surface composition of the particles. These HEA NPs present enhanced OER activities in contrast to their similar crystalline counterparts possibly due to the denser distribution of the defects, higher concentration of coordinatively unsaturated sites, and more loosely bonded atoms in the amorphous structures in addition to the synergistic effects arising due to the multimetallic combination. Hence, a need for more scientific research focused on this direction arises such that studies using methods like laser fragmentation [64] and addition/ replacement of the elements by more catalytically active ones for the aimed application could be considered to achieve further size reduction, amorphization, and higher defect density of the HEMG NPs. Altogether, the simplicity of PLAL in making highly complex HEMG nanostructures is explored with huge possibilities of tuning their performance together with the flexibility on the material system for potential applications in electrocatalysis.

\section{Acknowledgments}

S.-X. L. is grateful for the financial support from Alexander von
Humboldt Foundation Research Fellowship for postdoctoral researchers. The authors thank Friedrich Waag for fruitful discussions and for providing some of the HEA ablation targets. Jurij Jakobi is acknowledged for the XRF measurements.

Funding note: Open Access funding enabled and organized by Projekt DEAL.

Electronic Supplementary Material: Supplementary material (XPS peak-fitting parameters, chemical compositions of single NPs, HAADF-STEM image of $\mathrm{Cr}_{10} \mathrm{Co}_{10} \mathrm{Fe}_{10} \mathrm{Ni}_{10} \mathrm{Mn}_{30} \mathrm{Mo}_{30}$ NPs, SEM-EDX and XRF measurements of the HEA targets, HRTEM showing graphitic shell with Fourier transform, HRTEM, SAED patterns, and EDX linescans corresponding to the $\mathrm{Cr}_{10} \mathrm{Co}_{10} \mathrm{Fe}_{10} \mathrm{Ni}_{10}$ $\mathrm{Mn}_{30} \mathrm{Mo}_{30}$ and $\mathrm{Cr}_{14} \mathrm{Co}_{14} \mathrm{Fe}_{14} \mathrm{Ni}_{14} \mathrm{Mn}_{30} \mathrm{Mo}_{14}$ HEMG NPs, XRD diffractogram of $\mathrm{Cr}_{16} \mathrm{Co}_{16} \mathrm{Fe}_{16} \mathrm{Ni}_{16} \mathrm{Mn}_{30} \mathrm{Mo}_{06}$ HEMG NPs of size $<50 \mathrm{~nm}$, interplanar spacings, OER and ORR repetitions of $\mathrm{Cr}_{16} \mathrm{Co}_{16} \mathrm{Fe}_{16} \mathrm{Ni}_{16} \mathrm{Mn}_{30} \mathrm{Mo}_{06}$ NPs, Tafel slopes and data of $2^{\text {nd }}$ IP analysis, stability test of the catalysts in OER) is available in the online version of this article at https://doi.org/10.1007/s12274-0213804-2.

Open Access This article is licensed under a Creative Commons Attribution 4.0 International License, which permits use, sharing, adaptation, distribution and reproduction in any medium or format, as long as you give appropriate credit to the original author(s) and the source, provide a link to the Creative Commons licence, and indicate if changes were made.

The images or other third party material in this article are included in the article's Creative Commons licence, unless indicated otherwise in a credit line to the material. If material is not included in the article's Creative Commons licence and your intended use is not permitted by statutory regulation or exceeds the permitted use, you will need to obtain permission directly from the copyright holder.

To view a copy of this licence, visit http://creativecommons. org/licenses/by/4.0/.

\section{References}

[1] Lei, Z. F.; Liu, X. J.; Wu, Y.; Wang, H.; Jiang, S. H.; Wang, S. D.; Hui, X. D.; Wu, Y. D.; Gault, B.; Kontis, P. et al. Enhanced strength and ductility in a high-entropy alloy via ordered oxygen complexes. Nature 2018, 563, 546-550.

[2] Löffler, T.; Meyer, H.; Savan, A.; Wilde, P.; Manjón, A. G.; Chen, Y. T.; Ventosa, E.; Scheu, C.; Ludwig, A.; Schuhmann, W. Discovery of a multinary noble metal-free oxygen reduction catalyst. Adv. Energy Mater. 2018, 8, 1802269.

[3] Chen, P. C.; Liu, M. H.; Du, J. S.; Meckes, B.; Wang, S. Z.; Lin, H X.; Dravid, V. P.; Wolverton, C.; Mirkin, C. A. Interface and heterostructure design in polyelemental nanoparticles. Science 2019, 363, 959-964.

[4] Koo, W. T.; Millstone, J. E.; Weiss, P. S.; Kim, I. D. The design and science of polyelemental nanoparticles. ACS Nano 2020, 14, 6407-6413.

[5] Chen, P. C.; Liu, X. L.; Hedrick, J. L.; Xie, Z.; Wang, S. Z.; Lin, Q. Y.; Hersam, M. C.; Dravid, V. P.; Mirkin, C. A. Polyelemental nanoparticle libraries. Science 2016, 352, 1565-1569.

[6] Chen, P. C.; Liu, G. L.; Zhou, Y.; Brown, K. A.; Chernyak, N.; Hedrick, J. L.; He, S.; Xie, Z.; Lin, Q. Y.; Dravid, V. P. et al. Tipdirected synthesis of multimetallic nanoparticles. J. Am. Chem. Soc. 2015, 137, 9167-9173.

[7] Kwon, S. G.; Krylova, G.; Phillips, P. J.; Klie, R. F.; Chattopadhyay, S.; Shibata, T.; Bunel, E. E.; Liu, Y. Z.; Prakapenka, V. B.; Lee, B. et al. Heterogeneous nucleation and shape transformation of multicomponent metallic nanostructures. Nat. Mater. 2015, 14, 215-223. 
[8] Singh, M. P.; Srivastava, C. Synthesis and electron microscopy of high entropy alloy nanoparticles. Mater. Lett. 2015, 160, 419-422.

[9] Yang, Y.; Song, B. A.; Ke, X.; Xu, F. Y.; Bozhilov, K. N.; Hu, L. B.; Shahbazian-Yassar, R.; Zachariah, M. R. Aerosol synthesis of high entropy alloy nanoparticles. Langmuir 2020, 36, 1985-1992.

[10] Yeh, J. W.; Chen, S. K.; Lin, S. J.; Gan, J. Y.; Chin, T. S.; Shun, T. T.; Tsau, C. H.; Chang, S. Y. Nanostructured high-entropy alloys with multiple principal elements: Novel alloy design concepts and outcomes. Adv. Eng. Mater. 2004, 6, 299-303.

[11] George, E. P.; Raabe, D.; Ritchie, R. O. High-entropy alloys. Nat. Rev. Mater. 2019, 4, 515-534.

[12] Xin, Y.; Li, S. H.; Qian, Y. Y.; Zhu, W. K.; Yuan, H. B.; Jiang, P. Y.; Guo, R. H.; Wang, L. B. High-entropy alloys as a platform for catalysis: Progress, challenges, and opportunities. ACS Catal. 2020, 10, 11280-11306.

[13] Miracle, D. B.; Senkov, O. N. A critical review of high entropy alloys and related concepts. Acta Mater. 2017, 122, 448-511.

[14] Pickering, E. J.; Jones, N. G. High-entropy alloys: A critical assessment of their founding principles and future prospects. Int. Mater. Rev. 2016, 61, 183-202.

[15] Buck, M. R.; Bondi, J. F.; Schaak, R. E. A total-synthesis framework for the construction of high-order colloidal hybrid nanoparticles. Nat. Chem. 2012, 4, 37-44.

[16] Lacey, S. D.; Dong, Q.; Huang, Z. N.; Luo, J. R.; Xie, H.; Lin, Z. W.; Kirsch, D. J.; Vattipalli, V.; Povinelli, C.; Fan, W. et al. Stable multimetallic nanoparticles for oxygen electrocatalysis. Nano Lett. 2019, 19, 5149-5158.

[17] Wang, X. Z.; Dong, Q.; Qiao, H. Y.; Huang, Z. N.; Saray, M. T.; Zhong, G.; Lin, Z. W.; Cui, M. J.; Brozena, A.; Hong, M. et al. Continuous synthesis of hollow high-entropy nanoparticles for energy and catalysis applications. Adv. Mater. 2020, 32, 2002853.

[18] Wu, J. X.; Tang, A. W.; Huang, S. P.; Li, J. M.; Zeng, L. X.; Wei, M. D. In situ confined $\mathrm{Co}_{5} \mathrm{Ge}_{3}$ alloy nanoparticles in nitrogendoped carbon nanotubes for boosting lithium storage. ACS Appl. Mater. Interfaces 2020, 12, 46247-46253.

[19] Amiri, A.; Shahbazian-Yassar, R. Recent progress of high-entropy materials for energy storage and conversion. J. Mater. Chem. A 2021, 9, 782-823.

[20] Fang, G.; Gao, J. J.; Lv, J.; Jia, H. L.; Li, H. L.; Liu, W. H.; Xie, G. Q.; Chen, Z. H.; Huang, Y.; Yuan, Q. H. et al. Multi-component nanoporous alloy/(oxy)hydroxide for bifunctional oxygen electrocatalysis and rechargeable $\mathrm{Zn}$-air batteries. Appl. Catal. B: Environ. 2020, 268, 118431

[21] Jin, Z. Y.; Lv, J.; Jia, H. L.; Liu, W. H.; Li, H. L.; Chen, Z. H.; Lin, X.; Xie, G. Q.; Liu, X. J.; Sun, S. H. et al. Nanoporous Al-Ni-Co-IrMo high-entropy alloy for record-high water splitting activity in acidic environments. Small 2019, 15, 1904180

[22] Glasscott, M. W.; Pendergast, A. D.; Goines, S.; Bishop, A. R.; Hoang, A. T.; Renault, C.; Dick, J. E. Electrosynthesis of highentropy metallic glass nanoparticles for designer, multi-functional electrocatalysis. Nat. Commun. 2019, 10, 3115.

[23] Dai, W. J.; Lu, T.; Pan, Y. Novel and promising electrocatalyst for oxygen evolution reaction based on $\mathrm{MnFeCoNi}$ high entropy alloy. J. Power Sources 2019, 430, 104-111.

[24] Qiu, H. J.; Fang, G.; Gao, J. J.; Wen, Y. R.; Lv, J.; Li, H. L.; Xie, G. Q.; Liu, X. J.; Sun, S. H. Noble metal-free nanoporous highentropy alloys as highly efficient electrocatalysts for oxygen evolution reaction. ACS Mater. Lett. 2019, 1, 526-533.

[25] Li, S. Y.; Tang, X. W.; Jia, H. L.; Li, H. L.; Xie, G. Q.; Liu, X. J.; Lin, X.; Qiu, H. J. Nanoporous high-entropy alloys with low Pt loadings for high-performance electrochemical oxygen reduction. $J$. Catal. 2020, 383, 164-171.

[26] Batchelor, T. A. A.; Pedersen, J. K.; Winther, S. H.; Castelli, I. E.; Jacobsen, K. W.; Rossmeisl, J. High-entropy alloys as a discovery platform for electrocatalysis. Joule 2019, 3, 834-845.

[27] Tsai, C. F.; Wu, P. W.; Lin, P.; Chao, C. G.; Yeh, K. Y. Sputter deposition of multi-element nanoparticles as electrocatalysts for methanol oxidation. Jpn. J. Appl. Phys. 2008, 47, 5755-5761.

[28] Yusenko, K. V.; Riva, S.; Carvalho, P. A.; Yusenko, M. V.; Arnaboldi, S.; Sukhikh, A. S.; Hanfland, M.; Gromilov, S. A. First hexagonal close packed high-entropy alloy with outstanding stability under extreme conditions and electrocatalytic activity for methanol oxidation. Scr. Mater. 2017, 138, 22-27.

[29] Wang, A. L.; Wan, H. C.; Xu, H.; Tong, Y. X.; Li, G. R. Quinary $\mathrm{PdNiCoCuFe}$ alloy nanotube arrays as efficient electrocatalysts for methanol oxidation. Electrochim. Acta 2014, 127, 448-453.

[30] Nellaiappan, S.; Katiyar, N. K.; Kumar, R.; Parui, A.; Deo Malviya K.; Pradeep, K. G.; Singh, A. K.; Sharma, S.; Tiwary, C. S.; Biswas, $\mathrm{K}$. High-entropy alloys as catalysts for the $\mathrm{CO}_{2}$ and $\mathrm{CO}$ reduction reactions: Experimental realization. ACS Catal. 2020, 10 , 3658-3663.

[31] Pedersen, J. K.; Batchelor, T. A. A.; Bagger, A.; Rossmeisl, J. Highentropy alloys as catalysts for the $\mathrm{CO}_{2}$ and $\mathrm{CO}$ reduction reactions. ACS Catal. 2020, 10, 2169-2176.

[32] Gao, S. J.; Hao, S. Y.; Huang, Z. N.; Yuan, Y. F.; Han, S.; Lei, L. C.; Zhang, X. W.; Shahbazian-Yassar, R.; Lu, J. Synthesis of highentropy alloy nanoparticles on supports by the fast moving bed pyrolysis. Nat. Commun. 2020, 11, 2016.

[33] Zhang, G. L.; Ming, K. S.; Kang, J. L.; Huang, Q.; Zhang, Z. J.; Zheng, X. R.; Bi, X. F. High entropy alloy as a highly active and stable electrocatalyst for hydrogen evolution reaction. Electrochim. Acta 2018, 279, 19-23.

[34] Löffler, T.; Savan, A.; Meyer, H.; Meischein, M.; Strotkötter, V.; Ludwig, A.; Schuhmann, W. Design of complex solid-solution electrocatalysts by correlating configuration, adsorption energy distribution patterns, and activity curves. Angew. Chem., Int. Ed. 2020, 59, 5844-5850

[35] Löffler, T.; Waag, F.; Gökce, B.; Ludwig, A.; Barcikowski, S.; Schuhmann, W. Comparing the activity of complex solid solution electrocatalysts using inflection points of voltammetric activity curves as activity descriptors. ACS Catal. 2021, 11, 1014-1023.

[36] Li, R.; Liu, X. J.; Wu, R. Y.; Wang, J.; Li, Z. B.; Chan, K. C.; Wang, H.; Wu, Y.; Lu, Z. P. Flexible honeycombed nanoporous/glassy hybrid for efficient electrocatalytic hydrogen generation. Adv. Mater. 2019, 31, 1904989.

[37] Wang, H. Y.; Wei, R.; Li, X. M.; Ma, X. L.; Hao, X. G.; Guan, G. Q. Nanostructured amorphous $\mathrm{Fe}_{29} \mathrm{Co}_{27} \mathrm{Ni}_{23} \mathrm{Si}_{9} \mathrm{~B}_{12}$ high-entropyalloy: An efficient electrocatalyst for oxygen evolution reaction. $J$ Mater. Sci. Technol. 2021, 68, 191-198.

[38] Pei, Y.; Zhou, G. B.; Luan, N.; Zong, B. N.; Qiao, M. H.; Tao, F. Synthesis and catalysis of chemically reduced metal-metalloid amorphous alloys. Chem. Soc. Rev. 2012, 41, 8140-8162.

[39] Ye, J. C.; Lu, J.; Liu, C. T.; Wang, Q.; Yang, Y. Atomistic freevolume zones and inelastic deformation of metallic glasses. Nat. Mater. 2010, 9, 619-623.

[40] Wang, W. H. High-entropy metallic glasses. JOM 2014, 66, 2067-2077.

[41] Zou, Y.; Wheeler, J. M.; Ma, H.; Okle, P.; Spolenak, R. Nanocrystalline high-entropy alloys: A new paradigm in hightemperature strength and stability. Nano Lett. 2017, 17, 1569-1574.

[42] Yao, Y. G.; Huang, Z. N.; Xie, P. F.; Lacey, S. D.; Jacob, R. J.; Xie, H.; Chen, F. J.; Nie, A. M.; Pu, T. C.; Rehwoldt, M. et al. Carbothermal shock synthesis of high-entropy-alloy nanoparticles. Science 2018, 359, 1489-1494.

[43] Wu, D. S.; Kusada, K.; Yamamoto, T.; Toriyama, T.; Matsumura, S.; Kawaguchi, S.; Kubota, Y.; Kitagawa, H. Platinum-group-meta high-entropy-alloy nanoparticles. J. Am. Chem. Soc. 2020, 142 13833-13838.

[44] Zhang, D. S.; Gökce, B.; Barcikowski, S. Laser synthesis and processing of colloids: Fundamentals and applications. Chem. Rev. 2017, 117, 3990-4103.

[45] Amendola, V.; Amans, D.; Ishikawa, Y.; Koshizaki, N.; Scirè, S.; Compagnini, G.; Reichenberger, S.; Barcikowski, S. Frontispiece: Room-temperature laser synthesis in liquid of oxide, metal-oxide core-shells, and doped oxide nanoparticles. Chem.-Eur. J. 2020 26, 9206-9242.

[46] Reichenberger, S.; Marzun, G.; Muhler, M.; Barcikowski, S Perspective of surfactant-free colloidal nanoparticles in heterogeneous catalysis. ChemCatChem 2019, 11, 4489-4518.

[47] Neumeister, A.; Jakobi, J.; Rehbock, C.; Moysig, J.; Barcikowski, S. Monophasic ligand-free alloy nanoparticle synthesis determinants during pulsed laser ablation of bulk alloy and 
consolidated microparticles in water. Phys. Chem. Chem. Phys. 2014, 16, 23671-23678.

[48] Johny, J.; Kamp, M.; Prymak, O.; Tymoczko, A.; Wiedwald, U.; Rehbock, C.; Schürmann, U.; Popescu, R.; Gerthsen, D.; Kienle, L. et al. Formation of $\mathrm{Co}-\mathrm{Au}$ core-shell nanoparticles with thin gold shells and soft magnetic $\varepsilon$-cobalt cores ruled by thermodynamics and kinetics. J. Phys. Chem. C 2021, 125, 9534-9549.

[49] Tymoczko, A.; Kamp, M.; Rehbock, C.; Kienle, L.; Cattaruzza, E.; Barcikowski, S.; Amendola, V. One-step synthesis of Fe-Au core-shell magnetic-plasmonic nanoparticles driven by interface energy minimization. Nanoscale Horiz. 2019, 4, 1326-1332.

[50] Shih, C. Y.; Chen, C. B.; Rehbock, C.; Tymoczko, A.; Wiedwald, U.; Kamp, M.; Schuermann, U.; Kienle, L.; Barcikowski, S.; Zhigilei, L. V. Limited elemental mixing in nanoparticles generated by ultrashort pulse laser ablation of $\mathrm{AgCu}$ bilayer thin films in a liquid environment: Atomistic modeling and experiments. J. Phys. Chem. C 2021, 125, 2132-2155.

[51] Lin, Z.; Yue, J.; Liang, L.; Tang, B.; Liu, B.; Ren, L.; Li, Y.; Jiang, L. L. Rapid synthesis of metallic and alloy micro/nanoparticles by laser ablation towards water. Appl. Surf. Sci. 2020, 504, 144461.

[52] Waag, F.; Li, Y.; Ziefuß, A. R.; Bertin, E.; Kamp, M.; Duppel, V.; Marzun, G.; Kienle, L.; Barcikowski, S.; Gökce, B. Kineticallycontrolled laser-synthesis of colloidal high-entropy alloy nanoparticles. RSC Adv. 2019, 9, 18547-18558.

[53] Shih, C. Y.; Streubel, R.; Heberle, J.; Letzel, A.; Shugaev, M. V.; Wu, C. P.; Schmidt, M.; Gökce, B.; Barcikowski, S.; Zhigilei, L. V. Two mechanisms of nanoparticle generation in picosecond laser ablation in liquids: The origin of the bimodal size distribution. Nanoscale 2018, 10, 6900-6910.

[54] Shih, C. Y.; Shugaev, M. V.; Wu, C. P.; Zhigilei, L. V. The effect of pulse duration on nanoparticle generation in pulsed laser ablation in liquids: Insights from large-scale atomistic simulations. Phys. Chem. Chem. Phys. 2020, 22, 7077-7099.

[55] Song, X.; Xiao, K. L.; Wu, X. Q.; Wilde, G.; Jiang, M. Q. Nanoparticles produced by nanosecond pulse laser ablation of a metallic glass in water. J. Non-Cryst. Solids 2019, 517, 119-126.

[56] Kwong, H. Y.; Wong, M. H.; Leung, C. W.; Wong, Y. W.; Wong, K. H. Formation of core/shell structured cobalt/carbon nanoparticles by pulsed laser ablation in toluene. J. Appl. Phys. 2010, 108, 034304.

[57] Liang, S. X.; Zhang, L. C.; Reichenberger, S.; Barcikowski, S. Design and perspective of amorphous metal nanoparticles from laser synthesis and processing. Phys. Chem. Chem. Phys. 2021, 23, 11121-11154.

[58] Sun, X. C.; Wang, J. Q.; Yin, Y. H.; Wang, H. B.; Li, S.; Liu, H.; Mao, J.; Du, X. W. Laser-ablation-produced cobalt nickel phosphate with high-valence nickel ions as an active catalyst for the oxygen evolution reaction. Chem.-Eur. J. 2020, 26, 2793-2797.

[59] Schade, O. R.; Stein, F.; Reichenberger, S.; Gaur, A.; Saraçi, E.; Barcikowski, S.; Grunwaldt, J. D. Selective aerobic oxidation of 5(hydroxymethyl)furfural over heterogeneous silver-gold nanoparticle catalysts. Adv. Synth. Catal. 2020, 362, 5681-5696.

[60] Shih, C. Y.; Wu, C. P.; Shugaev, M. V.; Zhigilei, L. V. Atomistic modeling of nanoparticle generation in short pulse laser ablation of thin metal films in water. J. Colloid Interface Sci. 2017, 489, 3-17.

[61] Nobbmann, U.; Morfesis, A. Light scattering and nanoparticles. Mater. Today 2009, 12, 52-54.

[62] Barcikowski, S.; Amendola, V.; Lau, M.; Marzun, G.; Rehbock, C.; Reichenberger, S.; Zhang, D. S.; Gökce, B. Handbook of Laser Synthesis \& Processing of Colloids, 2nd ed.; DuEPublico 2: Essen, Germany, 2019. https://duepublico2.uni-due.de/receive/duepublico_ mods_00070584 (accessed May 31, 2021).

[63] Rane, S. S.; Choi, P. Polydispersity index: How accurately does it measure the breadth of the molecular weight distribution? Chem. Mater. 2005, 17, 926.

[64] Ziefuß, A. R.; Reichenberger, S.; Rehbock, C.; Chakraborty, I.; Gharib, M.; Parak, W. J.; Barcikowski, S. Laser fragmentation of colloidal gold nanoparticles with high-intensity nanosecond pulses is driven by a single-step fragmentation mechanism with a defined educt particle-size threshold. J. Phys. Chem. C 2018, 122,
22125-22136.

[65] Dittrich, S.; Barcikowski, S.; Gökce, B. Plasma and nanoparticle shielding during pulsed laser ablation in liquids cause ablation efficiency decrease. Opto-Electron. Adv. 2021, 4, 200072.

[66] Haxhiaj, I.; Tigges, S.; Firla, D.; Zhang, X. R.; Hagemann, U.; Kondo, T.; Nakamura, J.; Marzun, G.; Barcikowski, S. Platinum nanoparticles supported on reduced graphene oxide prepared in situ by a continuous one-step laser process. Appl. Surf. Sci. 2019, 469, 811-820.

[67] Kohsakowski, S.; Seiser, F.; Wiederrecht, J. P.; Reichenberger, S.; Vinnay, T.; Barcikowski, S.; Marzun, G. Effective size separation of laser-generated, surfactant-free nanoparticles by continuous centrifugation. Nanotechnology 2020, 31, 095603.

[68] Guadagnini, A.; Agnoli, S.; Badocco, D.; Pastore, P.; Pilot, R.; Ravelle-Chapuis, R.; van Raap, M. B. F.; Amendola, V. Kinetically stable nonequilibrium gold-cobalt alloy nanoparticles with magnetic and plasmonic properties obtained by laser ablation in liquid. ChemPhysChem 2021, 22, 657-664.

[69] Nadarajah, R.; Tahir, S.; Landers, J.; Koch, D.; Semisalova, A. S.; Wiemeler, J.; El-Zoka, A.; Kim, S. H.; Utzat, D.; Möller, R. et al. Controlling the oxidation of magnetic and electrically conductive solid-solution iron-rhodium nanoparticles synthesized by laser ablation in liquids. Nanomaterials 2020, 10, 2362.

[70] Marzun, G.; Bönnemann, H.; Lehmann, C.; Spliethoff, B.; Weidenthaler, C.; Barcikowski, S. Role of dissolved and molecular oxygen on $\mathrm{Cu}$ and $\mathrm{PtCu}$ alloy particle structure during laser ablation synthesis in liquids. ChemPhysChem 2017, 18, $1175-1184$.

[71] Ding, Z. Y.; Bian, J. J.; Shuang, S.; Liu, X. D.; Hu, Y. C.; Sun, C. W.; Yang, Y. High entropy intermetallic-oxide core-shell nanostructure as superb oxygen evolution reaction catalyst. $A d v$. Sustain. Syst. 2020, 4, 1900105.

[72] Jung, H. J.; Choi, M. Y. One-pot synthesis of graphitic and nitrogendoped graphitic layers on nickel nanoparticles produced by pulsed laser ablation in liquid: Solvent as the carbon and nitrogen source. Appl. Surf. Sci. 2018, 457, 1050-1056.

[73] Lin, J. Y.; Xi, C.; Li, Z.; Feng, Y.; Wu, D. Y.; Dong, C. K.; Yao, P.; Liu, H.; Du, X. W. Lattice-strained palladium nanoparticles as active catalysts for the oxygen reduction reaction. Chem. Commun. 2019, 55, 3121-3123.

[74] Zhang, D. S.; Zhang, C.; Liu, J.; Chen, Q.; Zhu, X. G.; Liang, C. H. Carbon-encapsulated metal/metal carbide/metal oxide core-shell nanostructures generated by laser ablation of metals in organic solvents. ACS Appl. Nano Mater. 2019, 2, 28-39.

[75] Trucano, P.; Chen, R. Structure of graphite by neutron diffraction. Nature 1975, 258, 136-137.

[76] Kim, Y. J.; Ma, R.; Reddy, D. A.; Kim, T. K. Liquid-phase pulsed laser ablation synthesis of graphitized carbon-encapsulated palladium core-shell nanospheres for catalytic reduction of nitrobenzene to aniline. Appl. Surf. Sci. 2015, 357, 2112-2120.

[77] Lee, S. H.; Jung, H. J.; Lee, S. J.; Theerthagiri, J.; Kim, T. H.; Choi, M. Y. Selective synthesis of Au and graphitic carbon-encapsulated $\mathrm{Au}(\mathrm{Au} @ \mathrm{GC})$ nanoparticles by pulsed laser ablation in solvents: Catalytic Au and acid-resistant Au@GC nanoparticles. Appl. Surf. Sci. 2020, 506, 145006.

[78] Abdullaeva, Z.; Omurzak, E.; Iwamoto, C.; Ganapathy, H. S.; Sulaimankulova, S.; Liliang, C.; Mashimo, T. Onion-like carbonencapsulated $\mathrm{Co}, \mathrm{Ni}$, and $\mathrm{Fe}$ magnetic nanoparticles with low cytotoxicity synthesized by a pulsed plasma in a liquid. Carbon 2012, 50, 1776-1785.

[79] Liu, X. G.; Ou, Z. Q.; Geng, D. Y.; Han, Z.; Jiang, J. J.; Liu, W.; Zhang, Z. D. Influence of a graphite shell on the thermal and electromagnetic characteristics of $\mathrm{FeNi}$ nanoparticles. Carbon 2010, 48, 891-897.

[80] Zhang, H. M.; Liu, J.; Tian, Z. F.; Ye, Y. X.; Cai, Y. Y.; Liang, C. H.; Terabe, K. A general strategy toward transition metal carbide/carbon core/shell nanospheres and their application for supercapacitor electrode. Carbon 2016, 100, 590-599.

[81] Inoue, A. Stabilization of metallic supercooled liquid and bulk amorphous alloys. Acta Mater. 2000, 48, 279-306. 
[82] Zhang, L. C.; Jia, Z.; Lyu, F. C.; Liang, S. X.; Lu, J. A review of catalytic performance of metallic glasses in wastewater treatment: Recent progress and prospects. Prog. Mater. Sci. 2019, 105, 100576.

[83] Sun, J.; Sinha, S. K.; Khammari, A.; Picher, M.; Terrones, M.; Banhart, F. The amorphization of metal nanoparticles in graphitic shells under laser pulses. Carbon 2020, 161, 495-501.

[84] Guo, S.; Liu, C. T. Phase stability in high entropy alloys: Formation of solid-solution phase or amorphous phase. Prog. Natl. Sci.: Mater. Int. 2011, 21, 433-446.

[85] Kanitz, A.; Hoppius, J. S.; del Mar Sanz, M.; Maicas, M.; Ostendorf, A.; Gurevich, E. L. Synthesis of magnetic nanoparticles by ultrashort pulsed laser ablation of iron in different liquids. ChemPhysChem 2017, 18, 1155-1164.

[86] Mookerjee, A.; Saha-Dasgupta, T.; Dasgupta, I.; Arya, A.; Banerjee, S.; Das, G. P. A first-principles thermodynamic approach to ordering in binary alloys. Bull. Mater. Sci. 2003, 26, 79-89.

[87] Guillermet, A. F. The Fe-Mo (iron-molybdenum) system. Bull. Alloy Phase Diagrams 1982, 3, 359-367.

[88] Cai, W. Z.; Chen, R.; Yang, H. B.; Tao, H. B.; Wang, H. Y.; Gao, J. J.; Liu, W.; Liu, S.; Hung, S. F.; Liu, B. Amorphous versus crystalline in water oxidation catalysis: A case study of NiFe alloy. Nano Lett. 2020, 20, 4278-4285.

[89] Indra, A.; Menezes, P. W.; Sahraie, N. R.; Bergmann, A.; Das, C.; Tallarida, M.; Schmeißer, D.; Strasser, P.; Driess, M. Unification of catalytic water oxidation and oxygen reduction reactions: Amorphous beat crystalline cobalt iron oxides. J. Am. Chem. Soc. 2014, 136, 17530-17536.

[90] Hu, F.; Zhu, S. L.; Chen, S. M.; Li, Y.; Ma, L.; Wu, T. P.; Zhang, Y.; Wang, C. M.; Liu, C. C.; Yang, X. J. et al. Amorphous metallic NiFeP: A conductive bulk material achieving high activity for oxygen evolution reaction in both alkaline and acidic media. $A d v$. Mater. 2017, 29, 1606570.

[91] Laplanche, G.; Volkert, U. F.; Eggeler, G.; George, E. P. Oxidation behavior of the CrMnFeCoNi high-entropy alloy. Oxid. Met. 2016 , 85, 629-645.

[92] Douglass, D. L.; Gesmundo, F.; de Asmundis, C. The air oxidation of an austenitic $\mathrm{Fe}-\mathrm{Mn}-\mathrm{Cr}$ stainless steel for fusion-reactor applications. Oxid. Met. 1986, 25, 235-268.

[93] Douglass, D. L.; Rizzo-Assuncao, F. The oxidation of Fe-19.6Cr15.1Mn stainless steel. Oxid. Met. 1988, 29, 271-287.

[94] Tomboc, G. M.; Kwon, T.; Joo, J.; Lee, K. High entropy alloy electrocatalysts: A critical assessment of fabrication and performance. J. Mater. Chem. A 2020, 8, 14844-14862.

[95] Pauling, L. Atomic radii and interatomic distances in metals. J. Am. Chem. Soc. 1947, 69, 542-553.

[96] Lv, Z. Y.; Liu, X. J.; Jia, B.; Wang, H.; Wu, Y.; Lu, Z. P. Development of a novel high-entropy alloy with eminent efficiency of degrading azo dye solutions. Sci. Rep. 2016, 6, 34213.

[97] Vassalini, I.; Borgese, L.; Mariz, M.; Polizzi, S.; Aquilanti, G.;
Ghigna, P.; Sartorel, A.; Amendola, V.; Alessandri, I. Enhanced electrocatalytic oxygen evolution in Au-Fe nanoalloys. Angew. Chem., Int. Ed. 2017, 56, 6589-6593.

[98] Marzun, G.; Levish, A.; Mackert, V.; Kallio, T.; Barcikowski, S.; Wagener, P. Laser synthesis, structure and chemical properties of colloidal nickel-molybdenum nanoparticles for the substitution of noble metals in heterogeneous catalysis. J. Colloid Interface Sci. 2017, 489, 57-67.

[99] Basu, M. In-situ developed carbon spheres function as promising support for enhanced activity of cobalt oxide in oxygen evolution reaction. J. Colloid Interface Sci. 2018, 530, 264-273.

[100] Kulkarni, A.; Siahrostami, S.; Patel, A.; Nørskov, J. K. Understanding catalytic activity trends in the oxygen reduction reaction. Chem. Rev. 2018, 118, 2302-2312.

[101] Hu, S.; Goenaga, G.; Melton, C.; Zawodzinski, T. A.; Mukherjee, D. $\mathrm{PtCo} / \mathrm{CoO}_{x}$ nanocomposites: Bifunctional electrocatalysts for oxygen reduction and evolution reactions synthesized via tandem laser ablation synthesis in solution-galvanic replacement reactions. Appl. Catal. B: Environ. 2016, 182, 286-296.

[102] Brandiele, R.; Amendola, V.; Guadagnini, A.; Rizzi, G. A.; Badocco, D.; Pastore, P.; Isse, A. A.; Durante, C.; Gennaro, A. Facile synthesis of $\mathrm{Pd}_{3} \mathrm{Y}$ alloy nanoparticles for electrocatalysis of the oxygen reduction reaction. Electrochim. Acta 2019, 320, 134563.

[103] Filimonenkov, I. S.; Bouillet, C.; Kéranguéven, G.; Simonov, P. A.; Tsirlina, G. A.; Savinova, E. R. Carbon materials as additives to the OER catalysts: RRDE study of carbon corrosion at high anodic potentials. Electrochim. Acta 2019, 321, 134657.

[104] Yang, J. C.; Park, S.; Choi, K. Y.; Park, H. S.; Cho, Y. G.; Ko, H.; Song, H. K. Activity-durability coincidence of oxygen evolution reaction in the presence of carbon corrosion: Case study of $\mathrm{MnCo}_{2} \mathrm{O}_{4}$ spinel with carbon black. ACS Sustainable Chem. Eng. 2018, 6, 9566-9571.

[105] Park, H.; Schleker, P. P. M.; Liu, Z. G.; Kowalew, N.; Stamm, T.; Schlögl, R.; Eichel, R. A.; Heumann, S.; Granwehr, J. Insights into water interaction at the interface of nitrogen-functionalized hydrothermal carbons. J. Phys. Chem. C 2019, 123, 25146-25156.

[106] Johny, J.; Prymak, O.; Kamp, M.; Calvo, F.; Kim, S. H.; Tymoczko, A.; El-Zoka, A.; Rehbock, C.; Schürmann, U.; Gault, B. et al. Multidimensional thermally-induced transformation of neststructured complex Au-Fe nanoalloys towards equilibrium. Nano Res., in press, DOI: 10.1007/s12274-021-3524-7.

[107] Zhang, D. S.; Liu, J.; Li, P. F.; Tian, Z. F.; Liang, C. H. Recent advances in surfactant-free, surface-charged, and defect-rich catalysts developed by laser ablation and processing in liquids. ChemNanoMat 2017, 3, 512-533.

[108] Bai, L.; Duan, Z. Y.; Wen, X. D.; Si, R.; Guan, J. Q. Atomically dispersed manganese-based catalysts for efficient catalysis of oxygen reduction reaction. Appl. Catal. B: Environ. 2019, 257, 117930. 